\title{
Later embryogenesis: regulatory circuitry in morphogenetic fields
}

\author{
Eric H. Davidson \\ Division of Biology, California Institute of Technology, Pasadena, CA 91125, USA
}

\section{SUMMARY}

The subject of this review is the nature of regulatory processes underlying the spatial subdivision of morphogenetic regions in later embryogenesis. I have applied a non-classical definition of morphogenetic field, the progenitor field, which is a region of an embryo composed of cells whose progeny will constitute a given morphological structure. An important feature of such fields is that they have sharp spatial boundaries, across which lie cells whose progeny will express different fates. Two examples of the embryonic specification and development of such fields are considered. These are the formation of the archenteron in the sea urchin embryo and the formation of dorsal axial mesoderm in the Xenopus embryo. From these and a number of additional examples, from vertebrate, Drosophila, Caenorhabditis elegans and sea urchin embryos, it is concluded that the initial formation of the boundaries of morphogenetic progenitor fields depends on both positive and negative transcription control functions. Specification of morphogenetic progenitor fields, organization of the boundaries and their subsequent regionalization or subdivision are mediated by intercellular signaling. Genes encoding regionally expressed transcription factors that are activated in response to intercell signaling, and that in turn mediate signaling changes downstream, appear as fundamental regulatory circuit elements. Such [signal $\rightarrow$ transcription factor gene $\rightarrow$ signal] circuit elements appear to be utilized, often repetitively, in many different morphogenetic processes.

Key words: Xenopus, sea urchin, intercellular signaling, morphogenetic field, pattern formation

\section{INTRODUCTION}

We are at present inundated with descriptions of the transient regional expression of various transcriptional regulatory factors during development. Sometimes, in fortuitous cases, such patterns can be related simply to the ultimate morphological modules of the organism. So it is a seductive argument that in order to understand pattern formation we need only to unravel the upstream cis-/transinteractions that specify the regional expression of the regulatory factor(s) defining these patterns. However, it is apparent that for organisms that are cellular rather than syncytial at the time a transcription factor pattern appears, the relevant cis-/trans-interactions must in some crucial measure be subject to control through intercellular signaling processes. Unfortunately, on present evidence, the relations between signaling and regional transcription factor expression are rarely obvious or explicit. Furthermore, the downstream pattern formation events by which morphological development begins to occur are as yet only faintly illuminated, if at all, by observation of the initial pattern of transcription factor expression.

Embryogenesis begins with the processes by which an initial set of cell lineage and/or territorial specifications are established. The result of these processes is the institution of the first cohort of differential spatial patterns of gene expression. Comparative consideration of specification mechanisms in many embryonic forms leads to the conclusion that there are basically three different ways by which metazoan embryos set up their initial spatial transcriptional patterns, exemplified by the Caenorhabditis elegans/sea urchin mode of early embryogenesis (referred to previously, and below, in this essay, as Type 1 embryogenesis; Davidson, 1990, 1991); the vertebrate mode of embryogenesis (Type 2); and the syncytial mode of early development exemplified by Drosophila (Type 3). The latter two of these are likely evolutionary derivatives of the first, which is phylogenetically by far the most widespread. However, at more advanced stages, all forms of embryonic development seem very similar (Davidson, 1991), particularly in respect to the subject of this essay: the mechanisms underlying the early and mid-stage events of regional morphogenesis. The 'later embryogenesis' of my title thus refers to the period of development beginning with the establishment of the larval body plan, i.e., roughly speaking, gastrulation et seq. Classical embryologists developed the concept of the "embryonic field' in order to deal with their image of later vertebrate embryogenesis. To begin I define a subcase of the classical embryonic field concept, which is simpler, more precise, and more useful for mechanistic considerations. I then discuss two interesting examples of embryonic morphogenesis, viz. archenteron formation in the sea urchin embryo; and the stepwise morphogenesis of axial mesodermal structures in Xenopus. In later sections aspects of the underlying regulatory mechanisms are considered, that from many vertebrate, Drosophila and other examples seem quite general. As in the previous essays of this series (Davidson, 1989, 1990, 1991), I adopt the view that a key to spatial processes of 
development is conditional cell specification. An attractive molecular model for conditional specification is that regulatory proteins in previously unspecified embryonic cells are converted, by means of signals from other cells, into active factors that specify particular transcriptional activities.

\section{ANLAGEN AND MORPHOGENETIC FIELDS}

\section{i. Definitions: some classical and modern concepts}

In what follows I shall use the term progenitor field to denote specifically that region of an embryo that will give rise to a given morphological structure, including whatever regional subdivisions of that structure may ultimately arise (e.g., the gut; and ultimately the foregut, midgut and hindgut). Such a term is necessary in order to consider in a mechanistic way the regulatory and signaling functions required for specification of the cells that are the actual precursors of the structure. The region that is composed of these cellular precursors is defined as the progenitor field for the structure, in the strict sense that if a lineage experiment were carried out on the structure with a cell heritable tracer, the cells of the structure would be found to derive from cells of the progenitor field. Furthermore, the progenitor field has a precise boundary, so that if cells within this boundary were labeled with the lineage tracer their progeny would be found in the structure in question, while the progeny of cells outside the boundary give rise to other structures or morphological components. The progenitor field concept concerns those spatially disposed cellular elements from which a structure originates, and thus is not directly relevant to later migratory cells that might invade the structure once

\footnotetext{
*Brief historical note: embryonic field concepts before 1940: Spemann (1938) reviewed what was even then a series of quite diverse concepts and definitions of "embryonic field." To a modern eye most of these seem unacceptably metaphysical. Spemann's preferred meaning for what he called "the embryonic field concept" was essentially that it is an inductive system, that will give rise to some structure. The term and some of the meaning was borrowed originally from "inductive field" as used in physics (p. 297, 303 op cit). In Spemann's usage, for example, the archenteron roof of the urodele embryo is "at least one of the sources of the field" (p. 304 op cit) that produces the neural plate; the mesenchymal cells that Ross Harrison (1918) had shown to be capable of inducing forelimb buds produce a limb field; in the eye the optic cup produces a lens field, as shown by transplanting it to other regions (Spemann, 1938, p. 325). An essential, original property of Spemann's embryonic field concept was that the field is "an equipotential system" (a concept derived from Driesch, 1905), in that if divided the field might recreate a complete new structure (Spemann, 1938, pp. 34, 302). This of course is true only transiently, but the phenomenon prominently affected the metaphysical flavor of argument surrounding classical field ideology even as late as 1938. Some of this flavor can be gleaned from Spemann's remark that (in respect to) "the structure of the field, . . by its remaining whole after experimental partitions or augmentation of the material substrates, our intellect is puzzled by the same difficulties by which Driesch was led to establish the notion of entelechy" (his emphasis; entelechy was Driesch's early vitalistic notion that parts of embryos possess an innate capacity to determine their own perfect and complete form).

The classical embryonic field has no boundaries, but rather displays a graded potential for developmental morphogenesis. Huxley and de Beer (1934, pp. 221-238) gave many examples of embryonic and postembryonic fields in which, as they defined it, the extent of the field for different organs always exceeds the actual anlage or rudiment. Thus the Huxley-de Beer fields of a given embryo at any one stage often overlap. In their treatment the key feature of the field is the presence of morphogen gradients within it. This feature is used to explain the ability of the classically conceived embryonic field to recreate complete structures when the field is sectioned, as well as its apparent properties of orientation and self-organization. To quote Huxley and de Beer, "The original control of differentiation in all cases appears to be exerted in relation to what may be called a 'morphogenetic field.' Within these fields various processes concerned with morphogenesis appear to be quantitatively graded ..." (Huxley and de Beer, 1934, p. 274). Their 'gradient fields' could be of
}

it is specified, e.g., hematopoietic or neural cells. As used here, 'progenitor field' is essentially equivalent to the classical (and modern) usage of the originally German word anlage: Webster's International English Dictionary $\left(2^{\mathrm{d}} \mathrm{ed}\right.$., 1934), defines anlage as "Foundation or basis for subsequent development; rudiment; the first accumulation of cells in an embryo recognizable as the commencement of a developing part or organ."

The concept of the progenitor field or anlage, as used here, is narrower in essential respects than all classical embryonic field concepts, and differs completely from them in the following two ways: $(i)$ In their original classical definitions*, embryonic fields lack boundaries, while from a mechanistic standpoint, boundaries are essential and definitive aspects of the areas of cells constituting the progenitor fields for given structures; (ii) classical embryonic fields are not synonymous with the sets of cells from which the structure will develop. In one of his famous Silliman Lectures, entitled 'Embryonic Fields,' Spemann himself (1938, p. 303) clearly and succinctly pointed out this distinction: "We denote the field by the organ originating in it. But we must always keep in mind that the field by no means coincides, neither spatially nor logically, with the presumptive or the determined rudiment of that organ.', In the following I wish to discuss the specification, and the further development, of precisely what Spemann was at pains to exclude from his definition of embryonic field, viz. just those cells that $d o$ coincide with the presumptive rudiments of given morphological structures.

\section{ii. Progenitor field specification}

A priori, embryonic progenitor field specification must generally be a conditional, and therefore a signal-mediated

two forms i.e., either dynamic gradients, or passive gradients of morphogens (1934, op cit, pp. 310-320). Dynamic gradient theory was later developed in elegant ways to include parameters that would shape the morphogen concentration functions and might produce spatial discontinuities and shaped patterns (e.g., Turing, 1952; Meinhardt, 1982). To relate such morphogen concentration gradients to the behavior of cells, the cells are required to know what to do by their position in the shaped morphogen gradient, the intensity and composition of which they read and respond to (see e.g., Wolpert, 1971). These concepts of embryonic or morphogenetic fields are considerably different from those of Harrison and Spemann, and in fact Spemann himself expressed great reservations about gradient-based interpretations of embryonic fields (Spemann, Chapter 16, 1938). Furthermore, in modern usage the meaning of the term embryonic field is often again permuted. For example, in a recent review De Robertis et al. (1991) discuss limb buds, feather buds, fin buds, and wing buds. Apparent gradients of homeobox gene expression are observed within the buds, and these are interpreted by the authors as molecular manifestations of Huxleyde Beer embryonic gradient fields. However, in all of these fields sharp boundaries are manifest, and except for cells destined to become necrotic the areas giving rise to these buds, and the buds themselves, consist of the cellular progenitors of the respective structures. Thus this usage represents another redefinition of the classical concept, since homeobox regulators are nuclear proteins, and do not diffuse across the space occupied by the field, and since Huxley-de Beer fields do not correspond to anlagen. The classical terms 'embryonic field', 'morphogenetic field', and their relatives, now even more than in Spemann's day, have accumulated too many different designata, so that they fail to communicate any unique scientific concept The classical field might (depending upon the author) include not only all the cells that give rise to a given structure, but any other cells that are responsible for inducing it, plus all cells in that area that are competent to respond to this induction in ectopic experimental recombinations. Furthermore, classical field concepts do not easily lend themselves to mechanistic molecular interpretations based on cell function. Ingham and Martinez-Arias (1992) concluded a discussion of morphogenetic boundaries in the insect cuticle with the observation that while we are now achieving a molecular level understanding of cellular function at morphogenetic boundaries, "Fields are still a classical embryological concept. Perhaps that is what they will remain ..." The reason that this prediction is likely to be accurate lies in the essential nature of classical embryonic field concepts. 
process. Classical observers were particularly aware of this in the case of vertebrate embryos. In a sense the same conclusion follows from the broader range of experiments on other embryonic forms that demonstrated regulative capabilities. These experiments display the conditional respecification of sets of embryonic lineages, or regions of the embryo, that under particular circumstances give rise to morphological structures that they would normally not generate (for reviews and discussion of regulative development see Davidson, 1986, Ch 6; Davidson, 1990, 1991). Regulative capability implies that the embryonic cells involved have more potentialities than they express. The potentialities that they select depend on which signals they receive, as shown by the observation that when placed in an ectopic situation their state of specification changes.

The signaling processes by which progenitor field specification occurs in later embryogenesis must suffice to designate the position of the field with respect to the body plan; the cells to be included within it; and its boundaries. The targets of these signaling processes are likely to include genes that encode transcriptional regulators, since the cells within the progenitor field will express a different suite of downstream properties than those on the other side of its boundaries. An elementary relation between intercell signaling and resulting changes in transcriptional regulatory gene expression will appear frequently in the following, as we consider a variety of different examples of progenitor field specification.

\section{THE SEA URCHIN EMBRYO ARCHENTERON}

The development of the sea urchin embryo archenteron illustrates in a relatively uncomplicated way both the specification of a set of cells destined to give rise to a particular structure of the embryo, and its subsequent morphogenesis. The phrase 'relatively uncomplicated' applies to both aspects. Thus, unlike virtually all the examples of vertebrate morphogenesis considered by classical authors in the formulation of their morphogenetic field theory, morphogenesis of the archenteron in the echinoderm embryo involves no inductive interaction between laterally apposed 'germ layers.' The initial specification of the progenitor field for the archenteron, i.e., the vegetal plate of the blastula stage, occurs during cleavage. Except for one pigment cell progenitor produced by each clone at 9th cleavage (Cameron et al., 1991), all of the progeny of each vegetal plate clone in turn contribute to the archenteron or its circumferential base and, in the normal embryo, cells from no other clones contribute to this structure.

\section{i. Initial specification}

Sea urchin embryos are typical of what I have termed 'Type 1' embryos (Davidson, 1991). This designation refers to the initial mode of blastomere specification in embryogenesis. In evolutionary terms the Type 1 mode is undoubtedly very ancient, and includes such disparate forms as those of $C$. elegans, the spirally cleaving embryos of annelids and molluscs (except cephalopods), and invertebrate deuterostome embryos exemplified by those of echinoderms and ascidians. Type 1 embryos have one egg axis specified before fertilization. This is reflected in a polarized egg cytoarchitecture, and in the generation of cell lineages that are autonomously specified by inheritance of cytoplasmic components. These autonomous lineages are characteristically located in polar positions with respect to the primordial axis, and sometimes to the second axis as well. However, in most forms the majority of blastomere lineages are specified conditionally during cleavage, probably by means of short-range intercell signaling, occurring across certain of the canonical cleavage planes. The early lineage and cell fate assignments of Type 1 embryos are typically invariant, and their cleavage planes separate founder cells whose progeny will execute different fates. In addition to creating clones of cells that will differentiate in particular directions, it is probable that an essential function of the polar, autonomously specified lineages is to present signals that effect the specification of adjacent blastomeres. In this way, the axial organization of the Type $1 \mathrm{egg}$ is translated into a spatially organized set of differently specified lineage founder cells (reviewed by Davidson, 1990, 1991, 1986 Chapter 6; for conditional and autonomous specification in the two best known Type 1 embryos, see for $C$. elegans, Priess and Thomson, 1987; Schnabel, 1991; Bowerman et al., 1992; Goldstein, 1992; and for sea urchin embryos, Davidson, 1989; Ransick and Davidson, 1993). In Type 1 embryos the genomic transcriptional apparatus is active from the beginning of development, and spatial transcriptional patterns are instituted during cleavage, upon founder cell specification. In summary, a working model for how Type 1 embryos operate is that the plastic and pluripotential blastomeres are conditionally specified in their fixed positions, by signaling ligands emanating from polar, autonomously specified blastomeres, as well as from one another. Blastomeres in given positions are thus defined as particular lineage founder cells, and thereupon they begin to function differentially at the transcriptional level.

In the sea urchin embryo the initial specification processes generate five transient, polyclonal territories, each defined by a distinct fate, and where studied, a distinct pattern of gene expression. These are indicated in the three-dimensional diagram shown in Fig. 1A. The progenitor field for the embryonic gut or archenteron is the vegetal plate territory, which derives from eight 6th cleavage founder cells (i.e., the blue cells of Fig. 1A), located in a ring just above the skeletogenic micromeres (i.e., the red cells of Fig. 1A). The plane of this ring is exactly perpendicular to the primordial animal-vegetal axis of the egg (Cameron et al., 1987, 1991). By the early blastula stage, the progeny of the vegetal plate founder cells have formed an open disc in the vegetal hemisphere of the embryo, concentrically surrounding the progenitors of the skeletogenic mesenchyme, and eight 'small micromeres,' which are of different lineage and fate (these derive from the four pink hatched cells of Fig. 1A). The upper boundary of the gut territory abuts cells destined to become oral and aboral ectoderm (yellow and green cells of Fig. 1A). The relations shown in Fig. 1A are entirely consistent from embryo to embryo (Cameron et al., 1987, 1991; Cameron and Davidson, 1991). It is important to note that the origin of the boundary between the ectoderm and vegetal plate territories is the original 6th cleavage plane separating the eight gut territory founder cells from the 

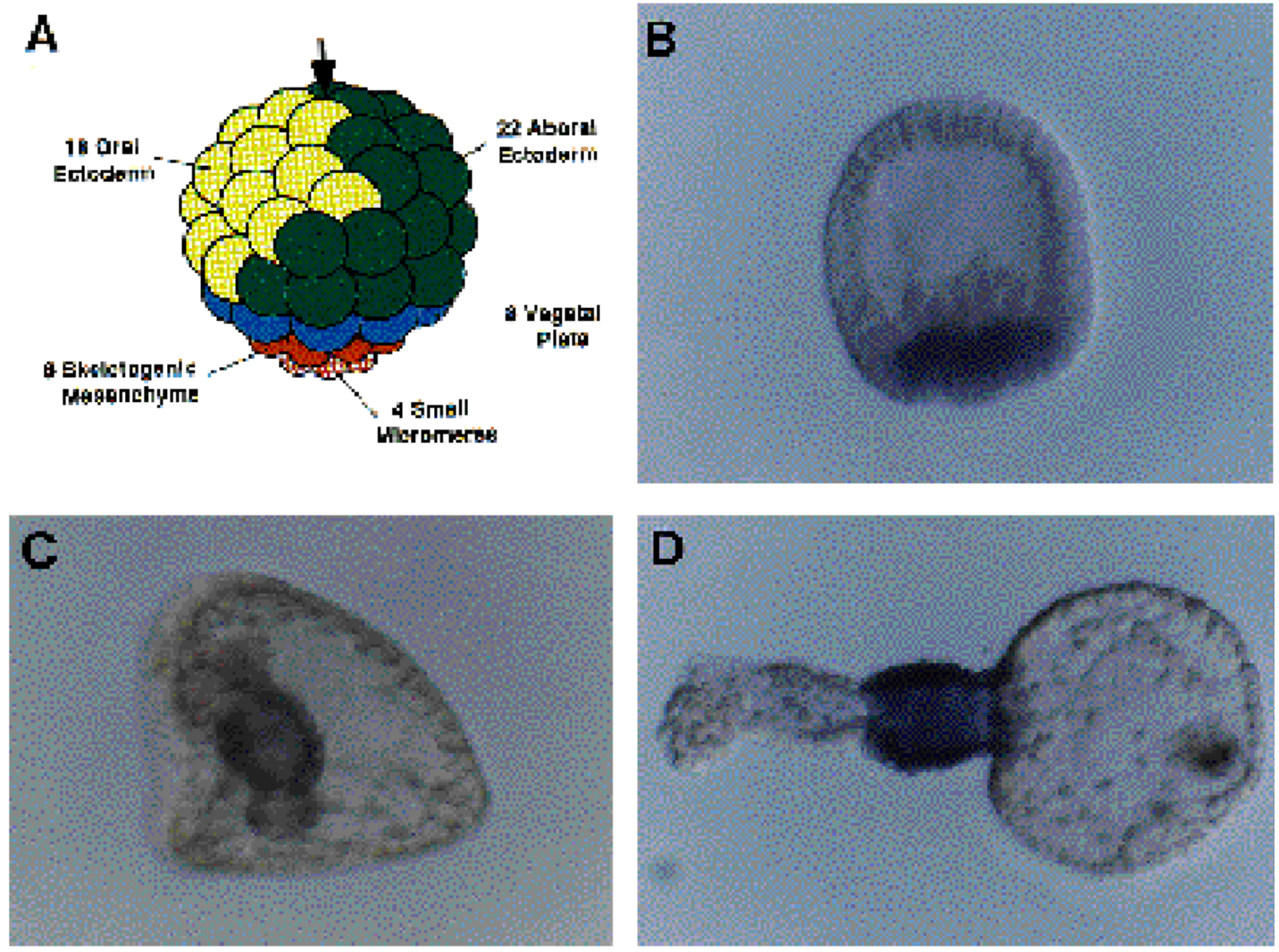

Fig. 1. Territories of the cleavage stage sea urchin embryo, and expression of the Endo-16 marker in vegetal plate and gut. (A) A threedimensional diagram displaying the five territories of the 6th cleavage embryo (see Davidson (1989) for discussion; Cameron and Davidson (1991) for cell types ultimately arising from each territory). The arrow at the top of the diagram indicates the animal pole. (BD) In situ hybridizations displaying location of Endo-16 transcripts. As shown in B this vegetal plate marker gene, which encodes a cell surface protein (Nocente-McGrath et al., 1989) is initially expressed at late blastula stage throughout the vegetal plate (excluding the eight small micromeres in the center; not visible here). The unlabeled cells in the blastocoel above the vegetal plate are the recently ingressed skeletogenic mesenchyme descended from the skeletogenic (red) cell layer of Fig. 1A. (C) A late gastrula, showing expression of Endo16 confined to the midgut, which gives rise to the stomach of the larva. $\mathrm{D}$ shows an exogastrula, produced by treatment with $\mathrm{LiCl}$ at cleavage stage. Endo-16 expression is again observed only in the midgut. Note that the exogastrula also produces secondary mesenchyme at the distal tip of the evaginated archenteron, foregut, and a compressed hindgut region that as in the normal embryo, does not express Endo-16. A is from Ransick and Davidson (1993) Science 259, 1134-1138. Copyright (1993) by the AAAS. B is from Ransick et al. (1993) Mech. Dev., in press; the embryos are Strongylocentrotus purpuratus.

overlying ring of sister cells. Ultimately the same boundary constitutes the border between the late blastula vegetal plate and the surrounding embryonic ectoderm. Thus in this case the boundary of a morphogenetic progenitor field for a gastrular structure derives entirely from one of the invariant planes of cleavage (a prevalent device in Type 1 embryos). At the late blastula stage, the skeletogenic precursors in the interior of the open disc formed by the progeny of the gut territory founder cells ingress into the blastocoel, leaving behind the definitive vegetal plate. The vegetal region of the blastula now consists exclusively of the eight archenteron progenitor clones, plus the eight cells of the small micromere lineage located exactly at the vegetal pole. At gastrulation the latter are carried inward on the distal end of the invaginating archenteron. Ultimately they are incorporated in the coelomic sacs that develop bilaterally on the sides of the archenteron tip late in gastrulation (Pehrson and Cohen, 1986; Tanaka and Dan, 1990; Cameron et al., 1991). In addition to its boundary with the ectoderm, the archen- teron progenitor lineages of the vegetal plate retain another spatial feature from the initial cleavage stage specification processes, viz. bilateral symmetry about the oral-aboral axis. This is manifested in the polarity and symmetry of the contributions to the coelomic sacs from the different quadrants of the vegetal plate (Cameron et al., 1991).

A useful marker for observing vegetal plate development is a gene called Endo16, which encodes a cell surface protein expressed exclusively in the gut territory and later in certain of its derivatives (Nocente-McGrath et al., 1989; Ransick et al., 1993). Fig. 1B shows that at the late blastula stage all of the cells of the definitive vegetal plate (i.e., except the small micromeres) equivalently express this gene. Following gastrular invagination, Endol6 is expressed throughout the archenteron, but as development proceeds, its transcripts disappear from the delaminating mesenchyme, and from the foregut, and hindgut. Expression of Endol6 is thus eventually confined to the midgut, i.e., the prospective stomach (Fig. 1C). The developmental pattern of Endo16 
expression nicely illustrates the progression from a bounded progenitor field of cells that initially all function equivalently, to a regionally differentiated, morphogenetic unit of the organism.

From the foregoing, it is clear that there is a direct and exclusive lineage relation between the eight founder blastomeres of the gut territory and the progenitor field for the archenteron, including its boundary with the ectoderm. Therefore, the initial specification of this field consists of the process by which the gut territory founder cells are specified during cleavage. Evidence from blastomere recombinations carried out by Hörstadius (1973, p. 59) initially suggested that the micromeres, which arise at the vegetal pole of the egg at 4th cleavage, might have the capacity to induce vegetal plate formation. A modern interpretation of this and much other related experimentation (Davidson, 1989) suggests that the vegetal plate founder cells are at least in part specified conditionally during cleavage, by short-range signals from the micromeres. Similarly, many of the founder cells for the oral and aboral ectoderm might also be conditionally specified by signals from adjacent cells, following an initial polarization in this axis. In contrast, the skeletogenic micromeres are autonomously specified. The progeny of the micromeres do not contribute in any direct way to the archenteron progenitor field. Excepting the micromeres and small micromeres and their derivatives, there is good evidence that any of the blastomeres of the embryo have the capacity to turn into gut territory founder cells; e.g., $\mathrm{LiCl}$ treatment causes animal cap blastomeres normally destined to become ectoderm founder cells to differentiate as gut, as does phorbol ester treatment (Livingston and Wilt, 1989, 1992). If cultured in contact with micromeres, isolated animal caps and animal cap blastomeres also express gut markers (Henry et al., 1989; Khaner and Wilt, 1991). Furthermore, a current study of Ransick and Davidson (1993) shows that a complete second archenteron can be induced to form by transplantation of four micromeres (i.e., the normal complement) to the animal pole of an otherwise undisturbed host embryo at the 8-cell stage. All of the normal structures of the differentiated archenteron are present in these secondary archenterons. Thus the ectopically placed micromeres have the capacity to convert blastomeres to which they are apposed, that are normally fated to produce oral and aboral ectoderm, into new gut territory founder cells. These in turn generate a new archenteron progenitor field that functions correctly. The Endo16 marker is expressed appropriately in both midguts, in the ectopic just as in the original archenteron (Ransick and Davidson, 1993). The experiment demonstrates that an ectopic vegetal plate can be specified by an entirely conditional mechanism in this embryo, by means of short-range inductive signals produced by micromeres. Whether there are additional localized factors present in the vegetal plate founder cells $a b$ initio, which may also facilitate gut territory specification in the undisturbed embryo, remains to be determined.

\section{ii. Morphological development of the vegetal plate}

Once specified, the morphogenetic development of the vegetal plate appears to proceed in an essentially autonomous manner. Thus, isolated vegetal plates carry out invagination and generate an archenteron (Ettensohn, 1984).
This process, which has been studied morphologically in great detail, occurs by convergent cell intercalation and rearrangement, and involves extensive changes in cytoskeletal organization, cell shape, and polarized cell motility (Ettensohn, 1984, 1985; Hardin and Cheng, 1986; Hardin, 1989; Cameron et al., 1991). Archenteron elongation across the blastocoel occurs without any further addition of cells. It seems obvious that the elongation process would require that each cell obtain information from adjacent cells regarding their polarity and position, and also that many specifically expressed gene products, both cytoskeletal and extracellular, would be required. Inhibitors that prevent the assembly of extracellular glycoproteins (Lennarz, 1983) and that interfere with polymerization of the collagenous components of the extracellular basal lamina (Wessel and McClay, 1987) both prevent archenteron invagination, suggesting that these are among the necessary extracellular components.

The independence of the molecular differentiation process by which the elongating archenteron is subdivided into mesenchyme, foregut, midgut and hindgut is demonstrated in Fig. 1D. This Fig. displays an exogastrula, induced by treatment with $\mathrm{LiCl}$. The morphological subregions are all visible in the extruded archenteron (as has been reported by many observers, classical and modern; see review of Lallier, 1964; and, e.g., Hardin and Cheng, 1986). Furthermore, Endol6 expression is confined, as expected, to the midgut. Therefore, archenteron diversification cannot depend on signals from the rest of the embryo that would be received directly by the distal tip, the foregut or the midgut regions. That is, a requirement for 'lateral' signals transferred via the blastocoel fluid, extracellular matrix, or filapodia extended from other cells cannot be involved. However, 'planar' signals connecting from the boundary at the base of the archenteron could indeed contribute to its ultimate regional diversification. In the exogastrula this boundary with the surrounding aboral ectoderm provides the only connection between the archenteron and other embryonic cell types.

It is not known how the tripartite differentiation of the extending archenteron into foregut, midgut and hindgut is spatially organized. By the time this stage of the process is complete (e.g., as in Fig. 1C, D), the distal end of the archenteron consists of motile secondary mesenchyme (mesoderm) cells, which are themselves probably pluripotential since they later participate in the formation of coelomic sacs, circumesophageal muscle, and migratory pigment cell and basal cell populations (reviewed by Cameron and Davidson, 1991). The adjacent region, i.e., the foregut, expresses different genes than does either mesenchyme or midgut. There are, for example, certain antigens recognized by monoclonal antibodies that are expressed in foregut but not midgut (Coffman and McClay, 1990) and other markers are expressed in hindgut as well as midgut (McClay et al., 1983; Wessel and McClay, 1985; Wessel et al., 1989). Endol6 is expressed solely in midgut, and a gene encoding profilin (Smith et al., 1992) is expressed only in the mesenchyme cells at this stage (unpublished data of L. C. Smith and the author). Furthermore, at the boundaries separating foregut and midgut, and midgut and hindgut, cells appear that express muscle molecular markers, viz. myosin heavy chain 
(Wessel et al., 1990) and a sea urchin myoD (Venuti et al., 1991). Contractile sphincters later develop at these locations. One possibility is that the spatial diversification of the archenteron depends in an immediate way on a radial disposition of maternal factors originally localized in the egg. However, it is hard to imagine how this would work, given that the four products of the future archenteron (mesenchyme, foregut, midgut, hindgut) all derive from progeny of a single ring of eight cells, each of which has been shown by lineage tracing to contribute, irregularly, to all four archenteron derivatives (Cameron et al., 1991; Hardin, 1989). Furthermore, this idea runs contrary to the evidence reviewed above that founder cell specification for the gut territory is, or at the very least, can be entirely conditional. Alternative kinds of regional specification processes can easily be imagined. For example the initial differentiation of the mesenchyme cells could be triggered by their distal-most position in the archenteron, once invagination has begun. The cells whose progeny express secondary mesenchyme functions are the only cells in the single cell thick archenteron column that are not contacted on all sides by other cells. To account for establishment of foregut, midgut and hindgut, and of the boundaries between them, some intercell signaling processes must be invoked. This leaves us with two possible classes of explanation. The boundaries could be established initially by radially oriented intercellular interactions occurring in the vegetal plate before invagination. Thus the subregions would be represented by concentric rings of vegetal plate cells in which the most central are specified to give rise to the most distal region of the archenteron (i.e., secondary mesenchyme and foregut) and the most peripheral in the vegetal plate to the most proximal (i.e., hindgut) region of the archenteron. However, there is no hint of radial specification in the uniform pattern of expression of vegetal plate markers such as Endo16 RNA (Ransick et al., 1993). The alternative is that signaling leading to regional diversification occurs during archenteron elongation, and until this time all vegetal plate cells that contribute to the archenteron and its structures are in fact equivalent. Though (in my view) the results of lineage studies, blastomere recombinations, and other experimental evidence all militate in favor of some version of this latter alternative, no conclusive arguments are yet available. In either case the main point is that internal diversification of the archenteron progenitor field must involve intercell signaling, which in turn controls transcriptional regulatory functions (such as control of Endo 16 expression) within particular subregions and at their boundaries.

Further morphogenesis of the gut clearly involves direct contact signaling between different embryonic cell types, as is also the case for other morphogenetic activities occurring late in embryogenesis. Thus in its final phase of elongation, which is not autonomous, the archenteron is steered to its ultimate target by secondary mesenchyme cells which contact the oral ectoderm. Hardin and McClay (1990) showed in a remarkable series of experiments that secondary mesenchyme cells on the archenteron tip extend long filapodia which ceaselessly explore the internal ectodermal wall until they locate the oral target site. Changes in adhesivity and cell shape thereupon ensue, and the directionality of the archenteron extension process changes so that the tip is brought into position for mouth formation at the archenteron-ectoderm junction. Though they lie outside the scope of this discussion, interactions at the oral-aboral ectoderm boundary are probably also responsible for generation of the ciliary band (Cameron et al., unpublished data), and contact interactions between the ectodermal wall and the skeletogenic mesenchyme cells position the assembly of the larval skeleton (Hardin et al., 1992; reviewed by Ettensohn and Ingersoll, 1992). Important interactions also occur between secondary mesenchyme and skeletogenic mesenchyme cells (reviewed by Ettensohn, 1992). In the present context, the archenteron provides a particularly interesting case as it carries out an extensive morphological and functional subregional diversification, prior to and independent of new contacts with any other cell types. Archenteron formation in the sea urchin embryo thus provides a relatively simple case of the general developmental phenomenon with which we are here concerned: the specification and the subsequent internal diversification of a discrete morphogenetic progenitor field.

\section{THE FORM OF REGULATORY INTERACTIONS IN THE REGIONAL SPECIFICATION OF DORSAL MESODERM IN XENOPUS EMBRYOS}

We turn now to the Xenopus embryo, and in particular, to the morphogenetic process that leads to specification of the dorsal mesoderm. There is a uniquely rich and complex assemblage of data relevant to the mechanism of this process. The intent of this section is to focus on the sequence of signaling and transcriptional activities-observed, implied or inferred-so as to extract a hypothetical interpretation that will serve as a basis for further consideration in other systems. To that end selected biological and molecular evidence for each stage of the process is considered in turn. For comprehensive treatments by workers in the field of Xenopus induction, which are more inclusive and less idiosyncratic in content and organization, the reader is referred to the authoritative reviews highlighted below.

Notochord, paraxial or somitic mesoderm, and the initial head or prechordal plate mesoderm are generated in amphibian embryos by a sequential series of intercellular signaling interactions. Though much studied, the definition of these interactions, either in cellular or in molecular terms, has proved a difficult, elusive problem. Viewed comparatively, there are a number of ways in which dorsal mesodermal morphogenesis in Xenopus differs from the process of archenteron formation in sea urchin embryos just considered. (a) In Xenopus, as in all vertebrate embryos, there is a variable cell lineage; therefore early specification of given founder cells, followed by the apparently autonomous execution of a developmental program, cannot provide an explanation as in the sea urchin case. (b) As a corollary, the progeny of many of the blastomeres that are the targets of inductive specification events in the earlier stages of the Xenopus process contribute to several distinct structures (varying in different embryos). (c) Dorsoanterior specification involves progressively changing signaling interactions between apposed layers of cells of different origin and fate, long beyond the initiating events that occur in cleavage. (d) 
The initial inductive interactions occur between blastomeres that are transcriptionally quiescent. (e) The latter stages of the process involve interactions between expanding populations of migratory cells. (f) The interactions are mediated by diffusible inductive ligands at least some of which may act over a range of several cell diameters or more. In a general sense these are all characteristic features of vertebrate embryogenesis (Type 2 embryogenesis in my comparative classification: see Davidson, 1990, 1991, for references to relevant cell lineage studies, reviews, and supporting data and arguments).

A basic underlying similarity between dorsal mesoderm formation in Xenopus and archenteron formation in sea urchin embryos is that the initial progenitors are in both cases at least in part conditionally specified. Thus in both cases the blastomeres whose progeny will contribute to the respective structures receive signals from adjacent blastomeres, whose progeny are not included in these structures. In both cases, if these signals are experimentally provided to other blastomeres instead, then these may be specified to produce ectopic progenitor fields for the same structures. Thus in Xenopus embryos transfer of dorsal vegetal blastomeres that are endodermal precursors to the ventral side of an embryo will produce an ectopic second dorsal axis (see below), just as in sea urchin embryos transfer of micromeres that are skeletogenic precursors to the animal pole will produce an ectopic second gut.

The following treatment of the progressive specification of the inductive centers that give rise to the dorsal mesodermal axis relies essentially on the views of Gerhart et al. (1991) and Kimelman et al. (1992). ${ }^{*}$ We shall mainly be concerned in this essay with the specification events that precede most of the actual elongation of the axis, up to and including the early- to mid-gastrula stage (stage $10 \frac{1}{2}$ in Xenopus). Furthermore, the following concerns only mesodermal aspects of axial specification, as these suffice for the point in hand. Though they are indeed prominent aspects of amphibian organizer function, neither planar neural interaction nor mesoderm to neuroectoderm induction processes are discussed, except en passant. With respect to the dorsal axial mesoderm, from a cell lineage point of view, three different, successive populations of cells with inductive activity appear: the first, known as the Nieuwkoop Center, are cleavage stage blastomeres located on the future dorsal side. At least some of these are vegetal blastomeres, the progeny of which contribute directly to endoderm and little or not at all to mesoderm. Signals from the Nieuwkoop Center specify cells of the dorsal marginal zone, the progeny of which later contribute prechordal head mesoderm. Following the nomenclature of von Dassow et al. (1993), this set of cells is referred to in the following as the head

\footnotetext{
* Other coherent models for the process by which the dorsal axis arises in amphibian embryos have previously been put forward, in which the spatial aspects of mesodermal specification depend essentially on concentration clines of a few factors (e.g., Smith and Slack, 1983; Smith et al., 1985; Green et al., 1992). This section of the present essay concludes with discussion of a form of signaling regulatory circuitry that may underlie the various steps of the process described; however, that conclusion is not dependent on the details of these different models of the inductive process. The current molecular and cellular evidence for sequential inductive interactions would, I think, indicate the same form of underlying regulatory circuitry at the intracellular level, had this evidence instead been organized from the starting point of the theories of Smith and Slack (1983) or Green et al. (1992).
}

organizer. An initial role of the head organizer is apparently to specify cells located immediately above it, which become the body axis organizer. Progeny of these cells give rise mainly to the notochord, which as it extends forward interacts laterally with paraxial mesodermal precursors, specifying them as somitic dorsal mesoderm. The head and body axis organizers taken together are equivalent to the classical Spemann organizer, i.e., at the beginning of gastrulation. The cells of the head organizer involute early in the gastrular process (by stage $10 \frac{1}{2}$, in Xenopus), followed by the cells of the body axis organizer. There are of course other interactions involved in mesodermal specification as well, as noted briefly below. The identities of the signaling ligands are not unequivocally established, though there is strong evidence for certain roles of some ligands (or their relatives) in different portions of this multistep process. For the purpose of the following argument, dorsal mesoderm specification is considered by stages, first with respect to experimental evidence for the inductive interrelations, then with respect to the state of knowledge regarding the molecular effectors that may be involved.

\section{i. Initial specification of mesodermal precursors}

Both the initial specification of the Nieuwkoop Center, and the signaling functions by which it in turn specifies the organizer region of the late blastula, occur during the period of transcriptional quiescence that precedes the mid-blastula transition. Thus by late blastula stage, when transcription resumes, the blastomeres of the Nieuwkoop Center have already lost some of their inductive potency (in urodeles; Boterenbrod and Nieuwkoop, 1973; in Xenopus, Gimlich, 1986). Early cytoskeletal events that position the future Nieuwkoop Center and thereby determine the future dorsal pole and the dorsoventral $(\mathrm{D} / \mathrm{V})$ axis of the embryo were identified in a beautiful series of experiments by Gerhart and his associates (reviewed by Gerhart et al., 1989). Establishment of this axis depends on a cortical rotation of about $30^{\circ}$ with respect to the underlying egg cytoplasm, which occurs during the first cleavage cycle. Normally this rotation is potentiated by a cytoskeletal reorganization that is triggered by sperm entry and the subsequent events of fertilization. The plane of the rotation becomes the plane of bilateral symmetry, and its direction determines the future dorsal side. In some unknown way this rotation activates a signaling capacity in the vegetal blastomeres that inherit the egg cytoplasm on this side. This signaling capacity was initially inferred from blastomere transplantation and excision experiments carried out in the 1960s and 1970s on embryos of several amphibian species (for reviews see Gerhart et al., 1991; Nieuwkoop, 1977). More recently, crucial evidence has derived from experiments that make use of eggs that are 'ventralized' by vegetal UV irradiation at first cleavage, a treatment that affects the cortical cytoskeleton, prevents the necessary rotation, and results in eggs that have impaired or absent dorsal specification. These eggs fail to form a Nieuwkoop Center. In experiments on 64-cell stage embryos Gimlich and Gerhart (1984) showed that dorsal axial development of ventralized eggs can be restored by replacing as few as 1-3 dorsal vegetal blastomeres with blastomeres from unirradiated donor embryos. The blastomeres that are most active in giving rise to a func- 
tional Nieuwkoop Center after transplantation are localized in a small vegetal dorsal region of the embryo (Gimlich, 1985; Kageura, 1990). These transplantation experiments also confirm that any circumferential position on the recipient eggs can become the dorsal pole. Lineage tracer studies show explicitly that the vegetal blastomeres that display Nieuwkoop Center activity on transplantation do not themselves contribute progeny to the dorsoaxial mesodermal structures. Their progeny are instead ultimately incorporated in the floor of the gut. At least the potent vegetal blastomeres of the Nieuwkoop Center lie below the position of the cells that display organizer activity later in development (Gimlich and Gerhart, 1984; Kageura, 1990; reviewed by Kimelman et al., 1992; Gerhart et al., 1991). If these vegetal blastomeres on the dorsal side constitute the major cellular components of the Nieuwkoop Center, then their inductive functions might begin to be expressed very early in development. Thus specification of the overlying blastomeres which do contribute progeny directly to axial structures is probably already occurring as early as 4th-6th cleavage, since if transplanted at these stages, these blastomeres also suffice to rescue UV-irradiated eggs or to produce ectopic second axes (Gimlich, 1986; Gallagher et al., 1991). On the other hand, it cannot be excluded that the Nieuwkoop Center extends up across the equator of the egg ab initio, overlapping the domain later occupied by the organizer region of the late blastula stage. It would thus include both blastomeres whose progeny are destined only to produce endoderm, and blastomeres whose progeny include axial mesoderm derivatives. The experimental definition of Nieuwkoop Center cells is just that they are the dorsal blastomeres capable of inducing axial development when transplanted to UV-ventralized embryos at early to mid-cleavage stages, or of inducing second axes when transplanted to the submarginal ventral regions of normal embryos. An essential signaling function, required for dorsal axial specification, is implied in either case.

The formation of the Nieuwkoop Center on the future dorsal side appears to be superimposed on an early, conditional specification of marginal zone blastomeres all around the egg, which endows them with the basic capacity to generate progeny that express mesodermal functions. This specification depends on signals from the vegetal hemisphere blastomeres of all quadrants (reviewed by Kimelman et al., 1992). In the absence of the Nieuwkoop Center signals, only ventral mesodermal cell types and structures arise from the marginal zone cells, as in UV-irradiated eggs. The Nieuwkoop Center signals switch the fate of those cells that lie in the dorsal region of the marginal zone. Thus, creation of the organizers and the structures that arise from them require both the circumferential signals causing induction of mesoderm, and the localized Nieuwkoop Center signals.

Our interest here is in the molecular regulatory interactions at each stage of this process, to the extent that these can so far be inferred. A member of the fibroblast growth factor (FGF) family is very likely to be involved in the initial specification of the marginal zone cells all around the embryo as potential mesoderm precursors (Christian et al., 1992; Kimelman and Maas, 1992). The evidence leading to this conclusion includes the following: (a) Animal cap explants, which in control experiments express only ectoderm markers in culture, and which consist mainly of ectoderm and neuroectoderm precursors, produce 'ventral and lateral' mesodermal cell types if exposed to exogenous bFGF (Kimelman and Kirschner, 1987; Slack et al., 1987; Green et al., 1990). (b) Injection of an mRNA encoding a truncated bFGF receptor subunit that produces a dominantly functionless mutant of this tyrosine kinase receptor, causes failure of ventral mesodermal involution at gastrulation, an early functional marker of mesodermal precursor specification (Amaya et al., 1991). However, invagination does occur on the dorsal side in the bFGF receptor-negative embryos, and anterior mesodermal (head) structures still form in these eggs. Therefore, assuming that the bFGF receptor is indeed entirely inactivated, bFGF cannot be the only ligand involved in the early marginal zone specification process (Kimelman et al., 1992). (c) Maternal forms of various FGF's and their mRNAs are present in the Xenopus embryo (Kimelman and Kirschner, 1987; Kimelman et al., 1988; Isaacs et al., 1992). In summary, these and other experiments indicate that an FGF is probably a natural early specifier of mesodermal precursors in the marginal zone, and is required for posterior and lateral mesodermal cell type specification. However, additional signals are also likely to be required for this process. Among these is clearly activin, a form of which is also present in the unfertilized egg and early embryo (Asashima et al., 1991), as well as other members of the TGF $\beta$ family, such as DRV-4, which displays a strong ability to induce ventral forms of mesoderm (Jones et al., 1992a). Direct evidence for an early role of activin in mesodermal specification derives from experiments of Hemmati-Brivanlou and Melton (1992), in which mRNA encoding a dominant negative form of activin receptor was injected into Xenopus eggs. Some of these eggs fail to develop any mesoderm whatsoever, and they form no dorsal axis or head structures. Activation of a very early marginal zone marker of FGF-induced mesoderm, viz. the brachyury gene (vide infra), is also blocked by the mutant activin receptor. Therefore, activin may be required synergistically with bFGF for the initial circumferential specification of mesoderm, as well as for the various later inductive functions discussed below.

The identity of the ligands involved in the signaling process is important for the arguments that follow mainly because of the links to downstream function that might emerge. Efforts to identify the dorsalizing signals of the Nieuwkoop Center have so far produced several very inter-

\footnotetext{
* The animal cap of stage 7-9 (mid to late blastula) embryos is not an entirely naive, unspecified test system (for an excellent discussion of the problems of interpreting animal cap explant experiments see the recent review of Jessell and Melton, 1992). The animal cap already displays a dorsoventral polarization (presumably the result of early signals from the Nieuwkoop Center and/or from the prior rotational 'activation' of the cytoplasm on the dorsal side at first cleavage). Thus the response to various growth factors in dorsal animal cap fragments is different from that in ventral animal cap fragments (Sokol and Melton, 1991; Ruiz i Altaba and Jessell, 1991). Kimelman and Maas (1992) found that injection of bFGF mRNA into eggs causes the dorsal region of animal caps, isolated at gastrula stage, to express dorsal mesoderm markers, while the ventral regions express ventral mesodermal markers. In other words, in these experiments the presumptive ectodermal cells on the dorsal side of the animal cap behave like the initially pluripotential dorsal blastomeres overlying the Nieuwkoop Center. These blastomeres receive both the dorsal signal from the Nieuwkoop Center and the signals producing general marginal zone mesoderm specification, i.e., including bFGF. In contrast, the cells on the ventral side of the animal cap resemble ventral marginal zone cells, after bFGF mRNA injection.
} 
esting candidates, but remain inconclusive. Among these candidates are members of the wnt family of ligands. Injection of mRNAs encoding the Xenopus wnt homologues Xwnt-1 or Xwnt- 8 into vegetal blastomeres on the ventral side of normal 8-32 cell embryos has the striking effect of generating a second dorsal axis, including head structures, and thus mimics the results of transplanting Nieuwkoop Center blastomeres (Christian et al., 1991; Sokol et al., 1991). Similarly, injection of these mRNAs into the vegetal blastomeres of 8-32 cell embryos derived from UV-irradiated eggs rescues dorsoanterior axis formation (Sokol et al., 1991; Smith and Harland, 1991). Lineage tracing showed that like the vegetal blastomeres of the natural Nieuwkoop Center, the progeny of blastomeres receiving Xwnt-8 mRNA do not contribute directly to any axial mesodermal structures, and are found almost exclusively in the endoderm in tailbud stage embryos (Smith and Harland, 1991). These particular Xwnt molecules are not in themselves capable of direct mesodermal induction, and just as inferred for the endogenous Nieuwkoop Center signal, they behave as agents that must work together with other diffusible factors to produce dorsal axial specification. Thus Christian et al. (1992) showed that if Xwnt-8 mRNA is injected into 2-cell blastomeres, and an animal cap later isolated, only ectodermal fates are expressed in these cells on culture, just as in uninjected eggs. But if the animal caps from these embryos are also treated with bFGF, dorsal mesodermal markers are expressed, and anteroposterior structural differentiation is observed, while as noted above bFGF alone induces only ventral mesodermal differentiation in isolated animal caps. Xwnt-8 encoded by injected mRNA also functions synergistically with activin, causing dorsal mesoderm and head differentiation in animal cap explants from UV-irradiated eggs (Sokol and Melton, 1992). The implication of these and other similar experiments is that Xwnt-8 can act like the Nieuwkoop Center signal to specify dorsoanterior development from cells that are also responding to FGF and/or activin (such as those of the whole marginal zone in normal development). However, it is unlikely that Xwnt- 8 itself is the natural ligand emanating from the Nieuwkoop Center. The gene encoding it is expressed too late and in the wrong places, and one possibility is that in these experiments the exogenous wnt ligand is stimulating receptors that in the undisturbed embryo respond to different endogenous maternal wnt (or other) ligands (Christian et al., 1991; Moon, 1993). Another very interesting candidate that could be a Nieuwkoop Center signal of major importance is encoded by a recently isolated cDNA clone called noggin (Smith and Harland, 1992). The egg contains maternal noggin mRNA and the gene is also expressed zygotically. Injection of noggin mRNA into ventral blastomeres of UVtreated eggs also rescues axis formation, and again, the function of the injected blastomeres is purely inductive, since their own progeny appear only in endodermal tissues.

To summarize, dorsal axial specification depends initially on a signaling function from vegetal and perhaps equatorial blastomeres on the future dorsal side, that affects cells of the marginal zone. These signals, together with the signals that specify marginal zone competence for mesoderm formation all around the egg specify the fates of mesodermal progenitors in the dorsal midline. That is, the Nieuwkoop Center signals together with the marginal zone mesodermalizing signals of vegetal origin specify the head mesoderm progenitor field (the head organizer). Via signals from the latter, and perhaps to some extent directly as well, these two sets of signals are also required for specification of the notochord progenitor field (the body axis organizer). The inductive functions of these progenitor fields, with respect to the surrounding tissues, constitutes their 'organizer' activity. As discussed below, the primary effect of these signals is probably to activate the transcription of regulatory genes encoding DNA-binding transcription factors.

\section{ii. Successive populations of cells with inductive activity; successive 'organizers'}

In considering the circuitry that could be required in a complex, stepwise process such as mesoderm induction in the Xenopus embryo it is essential to know what cells are doing what, and to what their progeny give rise. The use of high resolution cell lineage tracers over the last few years, and the advent of in situ methods for detecting gene expression, have greatly improved perceptions of this process. The arguments that the head organizer and body axis organizer are separate entities are partly based on lineage considerations, in the context of experimental transplantations. Some of these arguments can be summarized as follows:

(a) The mesodermal progeny of the early gastrula stage body axis organizer are equivalent to the notochord anlage. The early gastrula organizer transplantations of Spemann and his school produced in some cases complete second axes, including head, notochord, paraxial somites, and many other induced mesodermal structures. These grafts probably often included both head and body axis organizers. In the classical experiments that established and explored this phenomenon the notochord of the ectopic axis was reported to derive largely from the graft rather than from the host embryo; the graft cells were distinguished from host cells by the use of species differing in cellular pigmentation, or by vital staining (reviewed by Spemann (1938) Chapter 7). In a detailed and informative experimental reexamination carried out on Xenopus, Smith and Slack (1983) used an HRP lineage tracer, and showed that a labeled orthotopic graft of the Spemann organizer region contributes to the notochord over its whole anterior/posterior (A/P) extent. In transfers to the ventral marginal zone the HRP marked progeny of the graft completely labeled the notochord of the induced second axis, besides this contributing only a few cells to the somites (Smith and Slack, 1983). The surrounding host cells are induced to generate a complete secondary series of adjacent mesodermal derivatives, i.e., somites, kidney, blood islands, etc., from dorsal to ventral, as well as the overlying neural plate. This result is consistent with cell lineage data obtained on early gastrula Xenopus embryos (Keller, 1976). Recent grafting experiments identify more particularly the dorsal mesoderm cells of the body axis organizer at stage $10 \frac{1}{2}$, viz. the 'deep cells' of this region. At least 50 such cells are required to induce an ectopic dorsal axis, in which the introduced cells again contribute mainly the notochord (Shih and Keller, 1992a). These experiments together all lead to the conclusion that the early gastrula stage cells that possess the inductive capacity to generate an ectopic body axis on trans- 
plantation are themselves mainly the notochord progenitors. The body axis organizer as a whole is more complex after stage $10 \frac{1}{2}$, consisting both of the mesodermal deep cells that give rise to the notochord, and a newly arisen, involuting epithelial layer that eventually forms part of the endodermal archenteron roof. This layer also displays some organizer properties if transplanted, and is essential for the organized extension of the notochord progenitors as gastrulation proceeds (Shih and Keller, 1992a).

(b) Progeny of the late blastula marginal zone cells ultimately contribute the head mesoderm (Gerhart et al., 1991; Keller, 1976; Dale et al., 1985; Keller et al., 1992a). Thus these marginal zone cells, the direct targets of the Nieuwkoop Center signals, are distinct from the cells that will constitute the body axis organizer, the progeny of which give rise mainly to the notochord. However, these cells are able to induce the formation of a notochord anlage, which has the inductive activities associated with the body axis organizer. Stewart and Gerhart (1990) concluded from a series of truncation and grafting experiments that at late blastula (stage 9) in Xenopus the region with organizer activity is 5-10 cells high, 10-20 cells wide, and 2-4 cells deep. At this stage all regions of the organizer are equivalent in potentiality and fate and are interchangeable. The inductive potency of these cells was shown by recombining a normal meridional half late blastula embryo bisected in the dorsal midline with a meridional half of an embryo derived from a UV-irradiated egg. The normal half thus includes one lateral half of the late blastula stage organizer, and use of a lineage tracer showed that the notochord anlage in these recombinants was inductively formed in part from cells of the UV-irradiated half (Stewart and Gerhart, 1990). Additional experiments (Stewart, 1990) show that in an equatorial recombinant a normal late blastula stage vegetal half can induce notochord formation from cells of an animal half derived from a UV-irradiated egg. Since the Nieuwkoop Center per se is no longer active by this stage, these experiments again demonstrate the inductive specification of the notochord anlage by the marginal zone organizer cells. Kaneda (1981) and Kaneda and Suzuki (1983) had shown earlier that the equivalent region of a very early gastrula stage Cynops (urodele) embryo induces apposed animal pole cells to form notochord in cultured recombinant explants, though the animal pole cells will not do this if cultured alone. Conversely, if a small patch of labeled ectoderm cells is transplanted to the dorsal marginal zone, they are induced to contribute to the notochord.

Of course these organizers do not exist in a vacuum. For example, caudalizing signals from the adjacent lateral marginal zone may be required to explain the process by which the mesoderm that involutes following the head mesoderm gives rise to progressively more posterior portions of the mesodermal mantle (reviewed by Gerhart et al., 1991). There is no A/P prepatterning within the head organizer. Thus in the meridional recombinants between UV-irradiated half embryos and normal half embryos, onehalf of a normal width head organizer can induce almost complete A/P head structures (Stewart and Gerhart, 1990); and if the donor organizer is truncated by removal of its lateral portions the result is loss of anterior-most structures even though the cells included would have contributed progeny to the more posterior structures of the head region. In general, the $\mathrm{A} / \mathrm{P}$ specification of the mesoderm seems to be organized during gastrulation and not before, and it may depend on progressive interactions with more lateral cells. In addition $\mathrm{A} / \mathrm{P}$ specification may be affected by retinoic acid, downstream of the early events discussed here (see, e.g., Ruiz i Altaba and Jessell, 1991; Slack and Tannahill, 1992; Sive et al., 1990).

\section{iii. Signals and immediate early responses in the developing axial mesoderm}

There are two striking features of the emerging molecular perspective on the inductive development of axial mesoderm. These are the immediate early activation of genes that themselves encode transcription factors; and the utilization of similar or identical signals in successive stages of the morphogenetic process. In the following these features are considered chronologically, as a chain of the form signal $\rightarrow$ response $\rightarrow$ signal $\rightarrow$ response, etc., in the progenitor fields that give rise to the dorsal axial mesoderm. For a comprehensive and synthetic review of currently available data on the molecular identities of signals that might be involved in mesoderm induction throughout the whole embryo, the reader is referred to Kimelman et al. (1992). In general, it seems clear that any lingering affections for a one-signal:one-embryonic-function interpretation should be suppressed, and that we are only beginning to appreciate the multiplicity of the signals that may actually be involved in mesoderm specification in Xenopus.

Transcriptional responses in the head organizer. The goosecoid transcription factor may be an immediate target of signals emitted by the Nieuwkoop Center in the late blastula (Cho et al., 1991a). This gene is activated at stage 8.5 upon resumption of transcription (Blumberg et al., 1991), and is expressed in about a $60^{\circ}$ arc of the dorsal marginal zone, centered on the dorsal midline (Cho et al., 1991a), i.e., in the dimensions and location of the head organizer (Stewart and Gerhart, 1990). Furthermore the goosecoid gene is not activated in UV-irradiated eggs that lack a Nieuwkoop Center, and in LiCl-treated eggs it is expressed all around the marginal zone (Cho et al., 1991a); these eggs behave as if the Nieuwkoop Center extends around the whole circumference of the embryo. Christian and Moon (1993) showed that injection of Xwnt-1 mRNA in early ventral blastomeres activates goosecoid in the induced secondary organizer. Expression of the goosecoid gene is also induced, in the absence of protein synthesis, by activin (Cho et al., 1991a). In the normal embryo a wnt ligand emanating from the Nieuwkoop Center might work synergistically with activin to cause goosecoid expression in the head organizer. Thus Sokol and Melton (1992) found that if Xwnt-8 mRNA is injected into UV-ventralized eggs, animal cap ectoderm explants isolated at blastula stage express goosecoid and produce head structures on treatment with activin. Ventral injection of goosecoid mRNA may itself cause the formation of a second axis (Cho et al., 1991a), though with very variable frequency; and the induced axes do not include head structures anterior of the auditory vesicles (Niehrs et al., 1993). Thus the goosecoid gene is unlikely to be the sole primary target of the Nieuwkoop Center signals. Another gene encoding a transcription factor that is expressed in the region of the head 
organizer in the involuting anterior mesoderm is Xlim1 (Taira et al., 1992). Xliml encodes a divergent homeodomain protein which shares an additional domain with the C. elegans regulators $l i n-11$ and $m e c-3$, and it is activated after the mid-blastula transition though there are some maternal transcripts present initially. As with goosecoid, Xliml expression is induced as an immediate early response to activin treatment (Taira et al., 1992), and neither responds to bFGF. It is not unlikely that there are additional transcription factors that respond to Nieuwkoop Center signals in the head organizer, probably including genes belonging to the Xenopus family of regulators homologous to the Drosophila forkhead and the mammalian liver HNF3 factors (see below). These are also induced by activin and not by bFGF (Dirksen and Jamrich, 1992; Ruiz i Altaba and Jessell, 1992).

Though goosecoid or other inductively activated transcription factors in the head organizer must function positively to specify the body axis organizer, a negative downstream function of goosecoid is also required. This is to inactivate Xwnt-8 expression (Christian and Moon, 1993). As soon as transcription is resumed, Xwnt-8 is expressed circumferentially throughout the marginal zone except in the region of the late blastula organizer where goosecoid is expressed. Christian and Moon (1993) showed that ventral injection of goosecoid mRNA prevents Xwnt- 8 expression on the ventral side of the blastula. Xwnt- 8 expression is apparently activated in the marginal zone by the initial circumferential 'mesodermalizing' factors, and in fact can be induced by activin in (ventral) animal cap cells (Christian et al., 1991; Christian and Moon, 1993). The lateral and ventral regions of the embryo where Xwnt-8 is expressed give rise to lateral and ventral mesodermal structures and cell types. Furthermore, ectopic dorsal Xwnt-8 expression interferes with organizer specification. Thus if Xwnt-8 expression is forced at blastula-gastrula stage in the dorsal blastomeres destined to give rise to the head organizer, the normal dorsal goosecoid repression of Xwnt-8 expression can be overridden (Christian and Moon, 1993). In these embryos defects arise resulting from failure of head organizer functions, such as failure of head mesoderm development, and failure of notochord induction.

While not initially confined to dorsal mesoderm, the Xenopus brachyury gene (Xbra) provides still another case of a probable transcriptional regulatory gene that responds immediately, without the need for protein synthesis, to factors known to be important in mesoderm induction, i.e., to both bFGF and activin (Smith et al., 1991). Xbra is expressed at early stages in the presumptive marginal zone mesoderm precursors all around the embryo, and later in a ring around the blastopore, the location of the involuting posterior mesoderm precursors, and specifically in the notochord as well. Animal caps isolated from eggs injected at the animal pole with $\mathrm{Xbra}$ mRNA express posterior mesodermal markers in culture (Cunliffe and Smith, 1992), and a mutation $(T)$ in the cognate gene in the mouse shows that its function is required for posterior mesoderm formation (Herrmann et al., 1990).

Signals that may specify the body axis organizer. The head organizer is specified as a result of receiving certain signals, and its function in the specification of the body axis organizer should involve the emission of new signals. There is significant evidence that one such signal could be an activin or related ligand. As we have already seen, an activin-like molecule is probably also utilized in earlier stages of mesoderm specification, and activins are implicated in later inductive interactions as well. The signals emitted from the head organizer should be able to substitute for it functionally, i.e., such signals should be able to induce a notochord anlage in uncommitted cells, the progeny of which should possess the inductive capacities of a body axis organizer. Activin, and activin plus other signaling factors in fact display this capacity. Thus, notochord markers and morphological structures are induced by soluble activins in cultured animal cap cells, even in experiments in which the animal cap cells are dispersed (Green and Smith, 1990; Thomsen et al., 1990; Sokol and Melton, 1991; Green et al., $1990,1992)$. As noted above ventralized animal cap explants prepared from UV-irradiated eggs that had been injected with Xwnt-8 mRNA also produce notochord if treated with activin (Sokol and Melton, 1992). A particularly apropos experiment for this discussion was carried out by Cooke (1989) in which new body axis organizers were essentially created out of animal ectoderm cells by injecting activin preparations (XTC-MIF, i.e., activin A) into the blastocoel at early- to mid-blastula stages (stages 7-8). Small grafts, labeled with a lineage tracer, were removed from the blastocoel roof and transplanted to the ventral marginal zone of stage 9 hosts. The adjacent host cells were efficiently induced to produce second body axes, of which the ectopic notochords were the only structures formed more or less entirely from progeny of the grafted cells. Similar results were obtained by Ruiz i Altaba and Melton (1989b), by inserting activin-treated animal cap grafts that had been labeled with rhodamine into the blastocoel. Activin B transcripts are first detected in the normal embryo after the midblastula transition, when zygotic transcription is reactivated, and activin A somewhat later (Thomsen et al., 1990), but there are other members of the TGF $\beta$ family also present in the early embryo (Asashima et al., 1991; Dale et al., 1992; Jones et al., 1992a).

Since notochord also arises in animal cap explants derived from eggs injected with Xwnt-8 mRNA and then treated with bFGF (Christian et al., 1992), the signals that specify the body axis organizer could also include FGF and wnt molecules. Directly or indirectly, ectopic noggin also causes the formation of notochord (Smith and Harland, 1992). Wnt or noggin signals could emanate from new transcription in the head organizer (or could have been retained in the dorsal midline cells from earlier Nieuwkoop Center activity). Whatever the identity of the signals that specify the body axis organizer, the essential point is that this is again a signal-mediated specification process.

Transcriptional regulatory response genes in the body axis organizer. The target genes of the signals that specify the body axis organizer also include genes encoding transcription factors (some of these same factors are also utilized in the cells of the head organizer, as discussed above). Several of the likely candidates are inducible by activins, e.g., the Xenopus forkhead-like genes XFKHI (or XFD-3), $X F D-1$ and pintallavis. All of these genes encode transcription factors related to the mammalian liver DNA binding 
factors $H N F 3 \beta \alpha$ and $H N F 3 \beta$ (Dirksen and Jamrich, 1992; Knöchel et al., 1992; Ruiz i Altaba and Jessell, 1992). Some forkhead-like genes may be expressed in the head organizer immediately following the mid-blastula transition, and continue to be expressed in the prospective head mesoderm (e.g., pintallavis; Ruiz i Altaba and Jessell, 1992). Those so far characterized are expressed during gastrulation in the region of the notochord anlage, and then specifically in the extending notochord, but not in the paraxial mesoderm, or only at low levels. That is, they are expressed in the initial and the extending body axis organizer. XFKH1 and pintallavis are also expressed in the floorplate region of the neural plate. However, the notochord expression of those genes is by this stage autonomous, in the sense that it persists in exogastrulae, while the neural plate midline expression does not. Transcription of these three forkheadlike genes is induced rapidly by activin, and for XFKHI and pintallavis this is shown to occur in the absence of protein synthesis, indicating that these are immediate activin target genes. The goosecoid gene is also expressed in the body axis organizer and continues to be expressed in the extending notochord until the neurula stage (Cho et al., 1991a). As noted above, goosecoid is also an activin response gene. The mouse version of goosecoid, which is expressed for only a few hours at the anterior end of the primitive streak, is also strongly induced by activin (Blum et al., 1992). Similarly, Xliml expression continues in the notochord as it extends along the dorsal midline (Taira et al., 1992). In summary, there is a set of notochord anlage- and extending notochordspecific transcription factors, the genes encoding which are immediate early targets of activin. This is consistent with the possibility that activin is a specification signal from the head organizer for the body axis organizer.

Another gene, Xnot, which encodes a divergent homeodomain factor, is also expressed in the body axis organizer during gastrulation. Xnot differs from the body axis organizer regulatory genes, just discussed, in that its expression is induced by FGF as well as by activin (von Dassow et al., 1993). FGF induction is in fact necessary, since in embryos injected with mRNA encoding the mutant FGF receptor (Amaya et al., 1991), Xnot expression in the notochord does not occur. All of this evidence suggests that there may be two signaling pathways (sequential or parallel) required for activation of transcriptional regulatory genes in the body axis organizer: one that includes activin, and one that includes FGF, perhaps together with a wnt factor since this combination also induces notochord (Christian et al., 1992; see also evidence of Hemmati-Brivanlou and Melton, 1992 and Sokol and Melton, 1992 with respect to the possibility of such a dual pathway). Negative regulation by the TGF $\beta$ relative DVR-4 may also be involved in locating the boundaries of Xnot expression, and thus perhaps of the notochord progenitor field. Thus injection of mRNA encoding DVR-4 mRNA extinguishes Xnot expression (von Dassow et al., 1993), and also prevents the appearance of notochord and dorsal muscle (Dale et al., 1992). Nonetheless, gastrular involution begins normally in embryos injected with DVR-4 mRNA. Thus the experimental DVR4 effect could be particular to the specification of the body axis organizer, and in the normal embryo be used to limit the lateral extent of this organizer.
Signals of the extending Spemann organizer. As the notochord grows forward along the dorsal midline it forms a lineage interface with the flanking paraxial mesoderm (Shih and Keller, 1992b). The notochord is at least the major source of signals that specify the paraxial mesoderm as prospective somitic muscle. Experiments on second axis formation induced by organizer transplantations, carried out at different gastrula stages (Spemann, 1938, Chapter VII; Slack and Forman, 1980; Smith and Slack, 1983; Cooke, 1989), have clearly revealed the secondary notochord/ paraxial somitic mesoderm boundary as a labeled graft/host lineage boundary (though the grafts always produce a few individual cells that escape this boundary and contribute to the paraxial somites). Explanted combinations of dorsal and ventral marginal zone cells yield a similar result (Smith et al., 1985). In the paraxial mesoderm, MyoD is strongly expressed in the cells immediately adjacent to the notochord, and its expression is activated in response to mesodermal induction in explants (Hopwood et al., 1989). An activin or related ligand again could be at least one of the signals that is emitted by the extending notochord, and that induces differentiation of somitic muscle from the mesoderm alongside. Isolated animal caps, if treated with activins, produce dorsal axial mesoderm (reviewed by Smith, 1989; Thomsen et al., 1990), and it is significant that if exposed from the mid-blastula stage, but no later, the animal caps generate notochord as well as dorsal muscle; however, induction of dorsal muscle occurs on exposure from the early gastrula stage as well (Green et al., 1990). Dorsal mesoderm can be induced experimentally by activin to form only in dorsal regions of the animal caps isolated at blastula stages, thus revealing the prior influence of the Nieuwkoop Center signals (Ruiz i Altaba and Jessell, 1991; Sokol and Melton, 1991; see note p. 672). The relevance of this observation is not completely straightforward because in the undisturbed embryo the animal cap ectoderm does not contribute significantly to the mesoderm. There is additional evidence as well that suggests that activins or similar molecules are amongst the signals emitted by the extending body axis organizer, that induce formation of dorsal muscle. Thus ectopic expression of an activin receptor, following early injection of the receptor mRNA, causes excess dorsal muscle to form in isolated animal caps, on treatment with low doses of activin (Mathews et al., 1992). Conversely, in embryos developing from eggs injected with the dominant negative activin receptor mutant, expression of all mesodermal markers is blocked (Hemmati-Brivanlou and Melton, 1992), as noted earlier. This includes muscle actin, a specific marker for the induced dorsal mesoderm. FGF may again be involved as well, since it induces muscle actin with enhanced efficiency in activin receptor blocked cells (Hemmati-Brivanlou and Melton, 1992), and since it enhances activin sensitivity in the induction of musclespecific expression (Green et al., 1992). Another signal that could be utilized for neural or mesodermal induction by the extended body axis organizer as gastrulation progresses is noggin, as zygotic noggin expression occurs in the notochord anlage, and later in the prechordal mesoderm as well (Smith and Harland, 1992). Furthermore, exposure of gastrula stage ventral marginal zone explants to soluble 
noggin protein induces them to elongate and express muscle actin (Smith et al., 1993).

Regional expression of homeobox regulators. By late gastrula stage many different homeobox regulators are being expressed in specific regional patterns in both the CNS and mesoderm in the Xenopus embryo (see Slack and Tannahill, 1992, for a useful reference list). In general, the establishment of the regional patterns of expression of these transcription factors must lie downstream of intercellular interactions, since formation of the tissues where they are expressed is inductive. Furthermore, many experiments now demonstrate directly that genes encoding such later expressed homeobox regulators can be activated experimentally in inductive tissue recombinations (e.g., HemmatiBrivanlou et al., 1990; Sharpe and Gurdon, 1990) and by relevant growth factors (e.g., Ruiz i Altaba and Melton, 1989a,b; Green et al., 1992; Hemmati-Brivanlou and Melton, 1992). As reviewed elsewhere (Slack and Tannahill, 1992; McGinnis and Krumlauf, 1992) there is also much evidence from perturbation of homeobox protein expression in Xenopus embryos, and of the forkhead-like factor pintallavis (Ruiz i Altaba and Jessell, 1992) that the normal function of these genes is required for subsequent morphogenetic processes. Regionally expressed homeobox genes may effect morphogenesis by controlling the intercellular interactions that drive morphogenetic processes and that provide their spatial organization (see Davidson, 1991 for arguments, based on Drosophila, mouse, and Xenopus evidence). An interesting case from Xenopus in this context is that of Xlhbox6, which is expressed along the spinal cord and in the underlying mesoderm (Cho et al., 1991b; Niehrs and De Robertis, 1991). Xlhbox6 mRNA was injected into both blastomeres of a 2-cell embryo, and at stage 8 (midblastula) the animal cap was explanted and several hours later transplanted into the blastocoel, as a test of organizer function. The result was induction of posterior secondary axes, in which the implanted cells contributed mainly somitic mesoderm while most of the induced structures were composed of host cells. Unless the animal cap explants also were treated with activin, defined notochordal structures were lacking. The key point here is that the experiment shows directly that Xlhbox6 expression causes an inductive function that requires signaling to the adjacent (i.e., host) cells. The goosecoid gene discussed above provides a similar example. Lineage tracing shows that when goosecoid mRNA is injected into ventral blastomeres, the progeny of these blastomeres induce adjacent cells to generate paraxial muscle in the second axes that form (Niehrs et al., 1993). Forced expression of goosecoid also stimulates the migratory involution of mesodermal cell layers during gastrulation. Both results indicate that the goosecoid gene must include signaling functions among its downstream targets.

\section{iv. Regulatory processes}

A certain form of regulatory circuitry seems to be utilized over and over throughout the stepwise inductive process reviewed here. An interpretation of these regulatory processes is as follows: Following the special signaling and activation devices employed by the Xenopus embryo during the period of transcriptional quiescence, there takes place at each stage: (a) intercellular signaling mediated by particu- lar ligands and their receptors, which (b) must result in activation of preexistent transcription factors so that, (c) transcription of regulatory genes encoding new transcription factors is induced. The expression of these new regulators is thereby spatially confined to the multicellular domains where the signal is received. The consequence is, (d) the transcriptional activation of genes encoding ligands, receptors, and ancillary machinery, which convert these multicellular domains into new signaling and response elements themselves. The repetitive quality of this design is illustrated in Fig. 2A (see legend). Prior to resumption of transcription all the key components are maternal, while thereafter the components that are schematically indicated are the products of zygotic transcription (though elements of the signal transduction machinery, and many of the ancillary transcription factors might remain maternal).

There are several curious features of this regulatory organization, which emerge from some of the results touched on above. One of these is that the same ligands, e.g., FGFs, activins and wnts, appear to have activity at several different stages of the process. The presentation of these ligands in particular regional domains of the embryo is transcriptionally controlled, i.e., after the midblastula transition. Perhaps families of signaling ligands (that can indeed be made to substitute for one another under forced experimental conditions) are encoded by genes whose regulatory systems respond to different combinations of transcription factors, even though the products of these genes are functionally similar. This idea is analogous to an early proposal regarding the functional meaning of cytoskeletal protein gene families, in particular the five cytoskeletal actin genes of the sea urchin (Lee et al., 1984). These encode nearly identical proteins but are expressed in strikingly different embryonic territories and cell types (Cox et al., 1986). The implication is that the evolutionary duplication of these genes provided a means of incorporating them in entirely different regulatory situations. At the product level they appear redundant; at the regulatory level they are not.

A second feature that is a basic characteristic of this morphogenetic system is the interposition, at each step, of transcriptional activations of genes encoding gene regulatory factors. Even in the meager state of current molecular level information, we are aware of multiple cases of transcription factor genes in the Xenopus embryo that are activated as immediate early responses to signaling ligands. This means such genes are the primary targets, and that the embryonic phenomenon of 'competence' requires that the competent cell possesses all the necessary activatable factors, the signal transduction machinery and the receptors needed to obtain transcriptional expression. The molecular response will then be limited only by the signal. But why are transcription factor genes the primary targets, rather than, say, the ligand genes whose expression the transcription factors control? The answer to this may lie in the concept of the polyfunctional gene battery: the newly expressed regional transcription factors are the governors of many different functions, and the coordinate control of these functions can be arranged if the genes executing them respond to the same transcription factor(s). For example, we saw above that the goosecoid factor probably exercises a direct negative effect on Xwnt8 expression, but it is also likely to positively control 


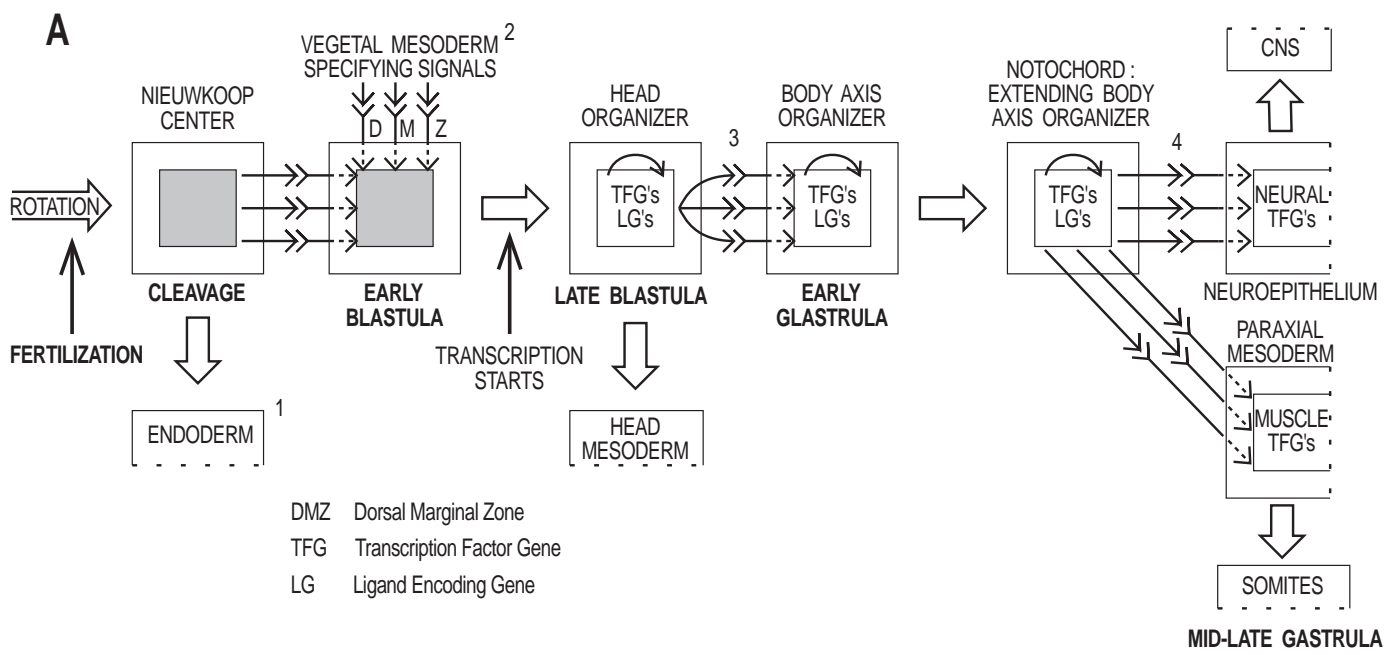

B

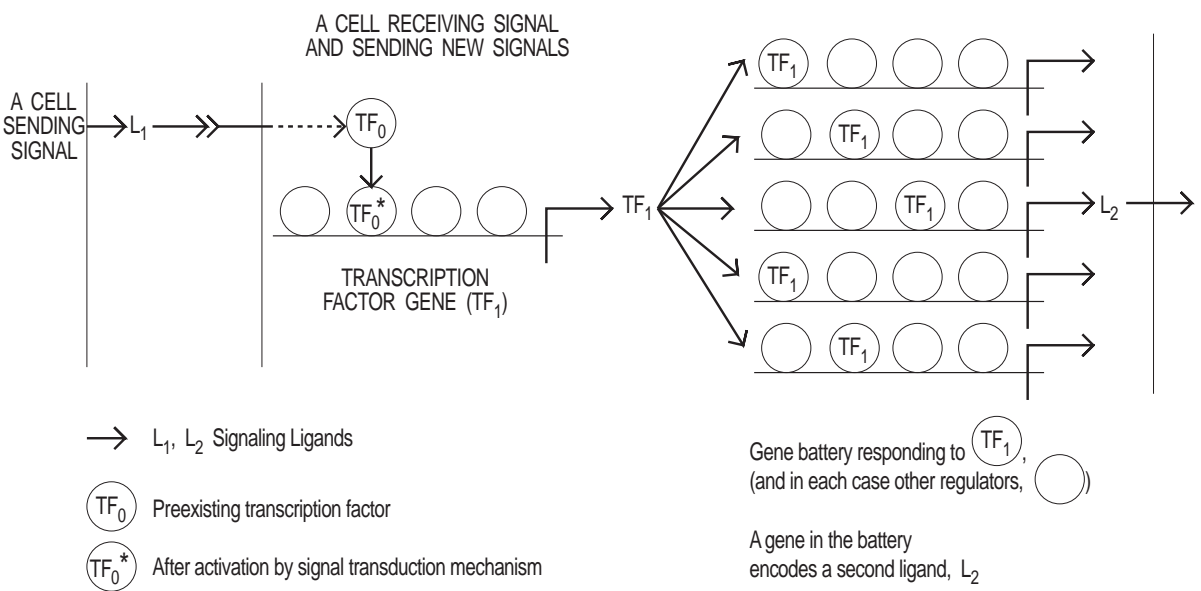

Fig. 2. The form of regulatory interactions inferred for the stepwise induction of dorsal axial mesoderm in Xenopus. (A) A very schematic, oversimplified diagram of the stages of axial mesoderm induction. The large boxes denote the multicellular components indicated just above them, and the small boxes within denote the nuclear compartments thereof. The components of the embryo to which each of the successive organizers gives rise as development progresses are indicated by the broad open arrows, i.e., each organizer is itself a progenitor field for the embryonic element at the other end of the open arrow to which it is connected. The small arrows indicate ligands (and ancillary extracellular molecules required for ligand presentation); and the Y-shaped symbols represent the receptors of these ligands. The dashed lines within each large box symbolize the cytoplasmic signal transduction events that result in the intranuclear activation of genes encoding transcription factors. These in turn result in transcriptional activation of genes encoding ligands within the same nuclei, as symbolized by the curved arrows within the nuclear compartments. The cross-hatching in the nuclear compartments of the two left-most boxes represents transcriptional quiescence prior to the midblastula transition. In this diagram, boxes bounded by dashed lines indicate continuing developmental processes not figured, as they lie beyond the confines of the discussion. The diagram is oversimplified in a number of respects, indicated by superscripts: ${ }^{1}$ Though dorsal vegetal cells are sufficient (for discussion and references see text), the Nieuwkoop Center may not be confined to vegetal cells that are exclusively endoderm precursors, as shown. That is, the Nieuwkoop Center might extend upward into the marginal zone so as to include blastomeres whose progeny also contribute to mesoderm. ${ }^{2}$ Though not shown here because only the dorsal sector of the embryo is represented in this diagram, these signals are expressed around the whole circumference of the egg. ${ }^{3}$ The signals that specify the body axis organizer may not derive exclusively from the head organizer, though the latter appears to suffice to induce a body axis organizer/notochord progenitor field. Body axis organizer specification could depend also on residual signaling molecules originating earlier on the dorsal side of the egg or in the Nieuwkoop Center. ${ }^{4}$ Only 'vertical,' i.e., mesoderm-to-neuroectoderm signals are included here, as the diagram concerns only dorsal mesoderm, though planar signals within the neuroectoderm are surely involved in CNS organization. Such planar signals may originate early in gastrulation, before notochord extension, in the body axis organizer. This feature is omitted from the diagram. (B) The predicted regulatory relationships symbolized within the nuclear compartments in A. Genes encoding transcription factors are activated by interactions at cis-target sites that respond to pre-existent factors when these are modified by signal transduction events; i.e., these transcription factor genes are immediate early response genes for the inductive signals (such mechanisms are now commonly observed in the physiological response systems of mammalian cells). The regulatory products of such genes are inferred to be required for expression (in combination with other factors, unspecified) of a battery of downstream genes. Among these are genes encoding ligands. That is, the cis-regulatory domains of these ligand genes will include target sites for the transcription factors expressed in response to inductive signaling. The same design suffices for each of the curved arrows represented in the nuclear compartment boxes in A. 
signaling, directly or otherwise. This in turn may involve a battery of genes in addition to the next ligand gene itself, including those encoding functions for its intercellular presentation and for ancillary extracellular proteins (vide infra).

A third feature of the design in Fig. 2A is that it requires transcription factor genes, up to the cell type-specific differentiation stage, to lie both upstream and downstream of intercellular signaling systems. Many observers have noted that homeobox genes are responsive to signaling ligands (e.g., in the context of the Xenopus embryo see Ruiz i Altaba and Melton, 1989b); others have noted that signaling systems are downstream of these genes, as discussed explicitly below. The morphogenetic process leading to axial specification of dorsal mesoderm in Xenopus consists at root of a chain of regulatory relationships, depending ultimately on transcriptional regulatory genes that operate both upstream and downstream of intercellular signaling systems.

At the target gene level the predictions of Fig. 2A are shown in a simplified cartoon in Fig. 2B. They are as follows: First, the ligand genes involved in processes such as mesoderm induction in the Xenopus embryo will be controlled by binding of the appropriate regionally expressed transcription factors, often homeodomain regulators. Second, the regionally expressed transcription factor genes will themselves be responsive to factors that depend for their activity on ligand/receptor mediated signal transduction events (or to factors encoded by other regulatory genes that are thus responsive). Third, both the genes encoding ligands and those encoding transcription factors must have multiple target sites for multiple factors (open circles in Fig. 2B) in their own regulatory domains. These are examples of what I have termed 'smart genes' (Davidson, 1990), in that they are required to integrate a variety of cell type specific or spatial, and temporal, regulatory information brought to the gene by the various factors that service it. Otherwise it is impossible to account for the repetitive utilization of the same signals, and the expression of the same transcriptional regulatory factors mediating distinct events in successive progenitor fields, at successive stages of the process.

\section{THE REGULATORY ENVIRONMENT OF GENES THAT CONTROL SPATIAL ASPECTS OF MORPHOGENETIC DEVELOPMENT: EVIDENCE FROM OTHER SYSTEMS}

\section{i. Upstream of regionally expressed morphogenetic transcription factors}

A general argument discussed earlier is that morphogenetic progenitor field specification in later embryogenesis is always conditional, and therefore that such fields are set up by intercellular signaling. Since the initial specification functions always involve regional activation of special transcription factors (or combinations thereof), signaling must always lie upstream of the expression of the genes encoding these factors. There is now much specific evidence supporting this inference in the vertebrate homeobox gene literature, but such considerations should not be confined to this class of regulatory gene, as similar functions may be mediated by HLH genes, steroid receptor family genes, Pax genes, forkhead-like genes, zinc finger genes such as the
Krox genes, etc. An external signal that affects expression of vertebrate Hox genes, both in cultured cells (Simione et al., 1990, 1991) and in vivo, is retinoic acid (RA), the effects of which are often correlated with morphological malformations. Though in some cases RA effects on Hox gene expression are apparently postranscriptional (reviewed by Tabin, 1991), transcriptional RA response elements have been identified in the cis-regulatory domains of several murine Hox genes (Langston and Gudas, 1992; Popperl and Featherstone, 1993). Many teratogenic effects of RA treatment on chick limb bud development that are tightly correlated with changes in Hox gene expression have been reported (e.g., Oliver et al., 1990; Yokouchi et al., 1991; reviewed by Tabin, 1991), and there are equivalent observations for both CNS and mesoderm of postneurula Xenopus embryos (e.g., Cho and De Robertis, 1990; Ruiz i Altaba and Jessell, 1991; Sive and Cheng, 1991). In the mouse, Kessel and Gruss (1991) described a striking late embryonic effect of RA on vertebral identity, to either more anterior or more posterior values depending on time of treatment, which is correlated in detail with segmental $\mathrm{A} / \mathrm{P}$ changes in combinatorial expression of various Hox genes, induced by the RA treatment. Factors of the TGF $\beta$ and bFGF families also affect homeobox gene expression in Xenopus embryos, as discussed above. In later vertebrate development there are striking cases in which precise spatial patterns of expression of TGF $\beta$ family members resemble closely the patterns of expression of particular homeobox genes (some examples are reviewed in Davidson, 1991). However, these correlations do not in general permit a decision as to whether expression of the ligand is upstream or downstream of expression of the homeobox gene. Direct genetic and molecular evidence is available in Drosophila, where expression of the TGF $\beta$ family ligand decapentaplegic ( $d p p)$ in visceral mesoderm is upstream of (i.e., required for) expression of the labial homeobox gene in the adjacent endoderm (Panganiban et al., 1990; Immerglück et al., 1990). A specific region of the labial gene control sequence has been found to contain target sites for a factor that depends on $d p p$ for activity (Tremml and Bienz, 1992). $d p p$ also represses the expression of $\mathrm{Scr}$ in the presumptive gastric caeca, and failure of this interaction leads to failure of caecal morphogenesis. In addition, $d p p$ expression is required to maintain $U b x$ expression in the visceral mesoderm.

The most direct evidence for signal mediated control of homeobox gene expression in a morphogenetic context in higher vertebrates comes from grafting experiments, particularly in limb buds. The Hox7 and Hox 8 genes of mice and chickens provide excellent examples (reviewed by IzpisúaBelmonte and Duboule, 1992; Muneoka and Sassoon, 1992). The patterns of expression of these genes in many tissues suggest that their activation is inductively controlled. Thus Hox7 is often expressed at the locus of inductive epithelial-mesenchymal interactions, e.g., in neural crest derivatives during head morphogenesis in the mouse, usually in either the epithelium or the mesenchyme, but sometimes in both interacting tissues (Mackenzie et al., 1991; Izpisúa-Belmonte and Duboule, 1992; Lyons et al., 1992). Several different signaling ligands may be involved in the control of Hox 7 expression in given contexts, 
including BMP2A, TGF $\beta 1$, wnt5a, and RA (Lyons et al., 1992). Hox7 and Hox8 are expressed in the limb buds of both mouse and chick, though in partially distinct patterns, at early stages when diversification of regional fates within the limb bud is becoming established. Both genes are initially expressed in the mesoderm on the anterior side of the bud, and expression of Hox 7 extends around to the distal mesoderm (the progress zone) immediately underlying the apical ectodermal ridge (AER). The AER is inductively required for the outgrowth of the limb, and for the ordered generation of its skeletal elements from proximal to distal, and Hox 8 but not Hox7 is also expressed in the AER itself (Coelho et al., 1991a, 1992a; Yokouchi et al., 1991; Davidson et al., 1991). Hox7 expression in the distal mesenchyme that constitutes the progress zone has been shown to be induced by a signal from the AER in several different grafting experiments. Proximal limb bud mesoderm placed in a distal position under the AER of a chick limb bud is, within hours, induced to activate the mouse Hox7 gene (Davidson et al., 1991). Similarly, if the AER from a quail leg bud is grafted over the proximal dorsal region of a chick wing bud, the underlying chick mesoderm, which now functions morphogenetically as an ectopic progress zone, expresses Hox7 (Robert et al., 1991). If the AER is removed, Hox7 expression in the progress zone disappears within a few hours (Ros et al., 1992). In limbless chicken mutants, which fail to generate an AER, Hox7 expression is not maintained in the distal mesoderm, though its initial expression is instituted independently of the AER (Robert et al., 1991; Coelho et al., 1991b). In limbless mutants a progress zone is not formed; however, both the Hox7 gene expression defect and the failure of limb outgrowth are corrected by grafting normal flank ectoderm onto the limbless wing bud (Robert et al., 1991). In limbless mutants, Hox 8 expression is also greatly depressed in the ectoderm of the AER region, and is perhaps required for the induction of Hox 7 expression in the subadjacent distal mesoderm (Coelho et al., 1991b). Another induction experiment involving a quail homologue of Hox8 was carried out by Takahashi et al. (1991), who showed in vitro that expression of this gene in branchial arch mesenchyme of the lower face is induced by signals from the arch epithelium. Transplantation experiments also show that expression of this gene is induced in overlying mesenchyme and ectoderm by the roof of the neural tube (Takahasi et al., 1992), and it is interesting that the relationship is reciprocal, in that a signal from the ectoderm is in turn required to maintain Hox 8 expression in the neural tube.

The expression of other homeobox genes in the limb bud is controlled by signaling as well. Thus expression of $5^{\prime}$ members of the Hox 4 complex in the distal mesoderm also requires signals of the AER, as shown by the effects of removal of the ridge in a variety of respecification experiments using retinoic acid (Izpisúa-Belmonte et al., 1992). The expression domains of the $5^{\prime}$ genes of the Hox 4 cluster are strikingly correlated with regional morphogenetic fate in such respecification experiments. For example, if the zone of polarizing activity (ZPA) at the posterior margin of the wing is transplanted to the anterior margin of a host wing bud a mirror image digit duplication is induced, preceded by a mirror image duplication of the Hox4.8 and Hox4.6 expression domains (Izpisúa-Belmonte et al., 1991). In diplopodia and talpid mutants, which produce extranumerary digits from the anterior mesoderm, the Hox4.6 gene is expressed ectopically on the anterior side as well as in its normal position on the posterior side of the limb bud; and the normal expression of the Hox 8 gene on the anterior side does not occur (Coelho et al., 1992b). As ZPA grafts mimic these effects, and also cause polydactyly (Izpisúa-Belmonte et al., 1991; Coelho et al., 1992b) it is evident that inductive control of the regional expression of homeodomain regulators is essential for correct $\mathrm{A} / \mathrm{P}$ morphogenesis just as for proximal distal morphogenetic differentiation.

To summarize thus far, we know from a great many experiments, both in vitro and in vivo, that various growth factors, when introduced experimentally, affect expression of homeobox gene regulators, some as immediate early responses (see above). In addition, for several higher vertebrate examples, particularly in limb buds, there is direct evidence for short-range inductive interactions that result in regional expression of specific homeodomain regulators. These undoubtedly are involved in the mid-stage regional diversification of morphogenetic structure.

The nature of the mechanisms that specify the initial loci of vertebrate limb bud progenitor fields remains unknown. An early marker of the forelimb progenitor field in Xenopus is the domain of expression in the lateral mesoderm of the Hox3.3 homologue (also called Xlhbox-1; Oliver et al., 1988). The homologous gene in zebra fish is similarly expressed in the lateral mesoderm that will become the pectoral fin bud, i.e., the structure homologous to the tetrapod forelimb bud (Molven et al., 1990). In Xenopus, mouse and zebra fish, as limb bud development proceeds, expression of this homeobox gene becomes confined to the anterior proximal region, and thus reflects the $\mathrm{A} / \mathrm{P}$ polarity of the bud (Oliver et al., 1988). The initial expression of this gene in the field of progenitor cells in limb or fin buds is an early, and relatively upstream function, and by the time these cells are committed to a limb bud fate, the original plasticity of Hox3.3 expression has disappeared. Thus transplantation of the posterior region of chick wing bud to the anterior region of a host wing bud, an operation that produces digit duplications, fails to turn on the Hox3.3 gene in the grafted tissue, irrespective of its now 'anterior' position. Correspondingly, if anterior mesoderm is implanted into the posterior region, the adjacent tissue is not induced to express this gene, nor is its expression in the graft negatively regulated (Oliver et al., 1990). In other words the regulatory responsiveness of this gene in the wing bud is evidently no longer required at the stage these transplants were carried out, and possibly its downstream functions also have been set in train by this stage.

\section{ii. Downstream functions of morphogenetically active homeobox genes include control of signaling systems}

A major function of homeodomain regulators, and other transcriptional regulators that are regionally expressed within morphogenetic progenitor fields, may be to control intercellular signaling systems (Davidson, 1991). In addition to genes encoding ligands and receptors, types of signal system genes that might serve as immediate targets for such 
regional transcriptional control factors could include genes encoding extracellular adhesion molecules that significantly mediate intercellular interactions (see review of Hynes and Lander, 1992). Cadherins are particularly interesting, because the spatial distribution of particular members of this family corresponds perfectly with certain morphogenetic anlagen during embryogenesis. For example in the axial structures of the vertebrate embryo, cells of the notochord express P-cadherin, while the adjacent somites and neural tube express $\mathrm{N}$-cadherin (reviewed by Takeichi, 1987, 1991). Prior to neural induction the presumptive neural epidermis expresses E-cadherin. Furthermore, in lateral morphogenetic inductions, both apposed tissues often express the same cadherin, just as they often express the same homeobox gene (cases of the latter are reviewed in Davidson, 1991; and many more examples have since appeared). Cadherins are essential downstream effectors of morphogenesis. Thus for example, if ectopic expression of $\mathrm{N}$-cadherin is forced by injection of the mRNA into Xenopus eggs, the consequences include abnormal ectodermal morphology, disorganization of the neural tube, clumping of somatic mesoderm, and failure of separation of the neural tube from the overlying ectoderm (Detrick et al., 1990; Fujimori et al., 1990). Similarly, antibodies against E- and $\mathrm{P}$-cadherin seriously derange inductive morphogenesis, both in mouse bronchial tubule and brain organ cultures (Hirai et al., 1989; Shimamura and Takeichi, 1992).

The first evidence that genes encoding ligands are among the direct downstream targets of homeobox genes came from analyses of Drosophila midgut morphogenesis carried out by Reuter et al. (1990) and Immerglück et al. (1990). These studies showed that spatial expression of $d p p$ (a TGF $\beta$ family member) and $w g$ (a wnt family member) ligands are controlled by the $U b x$ and $A b d-A$ genes. The activation of $d p p$ by $U b x$ in the visceral mesoderm is necessary for formation of a constriction in the midgut in parasegment 7. This is likely a direct effect, because immediate ectopic $d p p$ expression is induced in flies in which $U b x$ expression is caused to occur ectopically under the control of a heat shock promoter. In parasegment $8, A b d-A$ regulates $d p p$ expression negatively, preventing expression of the ligand gene in this parasegment. In addition expression of $A b d-A$ is at least one of the requirements for expression of $w g$ in the visceral mesoderm, in parasegment 8 , to which $w g$ expression is confined. The $w g$ factor apparently diffuses to the contiguous endoderm, where it may be required along with $d p p$ for the normal pattern of labial homeobox gene expression. In contrast to the direct effect of $d p p$ on labial gene expression, the effect of the $w g$ factor appears to be indirect (Tremml and Bienz, 1992). A second regionally expressed, downstream target of the $U b x$ homeodomain regulator, which is also probably involved in intercell interactions, is the connectin gene (Gould and White, 1992). This gene encodes a cell adhesion molecule, and its expression may be subject to control by other homeotic genes as well, including Antp.

$\mathrm{N}-\mathrm{CAM}$ appears to be a direct target of a homeobox regulator in mouse cells (Jones et al., 1992b). An $N$ $C A M \cdot C A T$ fusion gene was transfected into tissue culture cells together with sequences encoding Hox2.5 proteins under control of an active viral promoter, and the induced expression of CAT was shown to depend on intact cis target sites for the homeodomain protein. Similar experiments show that $E v x-1$, a mouse homeobox gene that encodes a protein similar to evenskipped of Drosophila, specifically induces expression of cytotactin, although in this case the effect is mediated via interactions at an AP1 site rather than directly (Jones et al., 1992c). The Pax genes may also control cell signaling systems, including cellular adhesion proteins, among their downstream functions (see review of Gruss and Walther, 1992). An interesting case is Pax-6, for which a series of mouse mutations called small eye are known (Hill et al., 1991). The phenotype of these mutations suggests that Pax-6 function is in some manner involved with downstream inductive interactions. Another group of mutations at the splotch locus affect the Pax-3 gene (Epstein et al., 1991) and among the downstream targets of this gene is a processing or regulatory system that controls N-CAM expression (Moase and Trasler, 1991).

\section{iii. Sequential interactions in lateral induction}

Fig. 1C, D demonstrate the progressive process of subdivision of the anlage for the sea urchin archenteron, which occurs in the absence of any possible inductive spatial instruction from laterally apposed tissue layers. This shows that continuing, instructive lateral signals, deriving from different apposed tissues in different regions of the structure, are not a sine qua non for internal diversification of a morphogenetic progenitor field. The same is undoubtedly true of the subdivision of the imaginal disc epithelium in the morphogenesis of the peripheral nervous system and of other structures in Drosophila (e.g., see reviews of Ghysen and Dambly-Chaudière, 1989; Moscoso del Prado and Garcia-Bellido, 1984). On the other hand, the majority of the vertebrate examples of morphogenetic induction discussed here appear to be mediated at least in part by continuing inductive interactions between apposed tissue layers. Since complex morphogenetic subdivisions can take place within a progenitor field in the absence of such interactions, the instructive role of lateral interactions might easily be overinterpreted when they do occur. Though it lies outside the scope of this essay, perhaps this is the significance of the growing body of evidence for the planar induction of a large amount of regional differentation in the amphibian central nervous system, at least up to the forebrain level, in experimental contexts that prohibit lateral interactions with the mesoderm (e.g., see Dixon and Kintner, 1989; Doniach et al., 1992; Keller et al., 1992b; Ruiz i Altaba, 1992).

Where progressive inductive interactions between apposed tissue layers are required, these may be two-way interactions, since both the 'inducing' and the 'induced' tissues change their state of differentiation and morphology. Change in morphology requires the assembly of new cytoskeletal and extracellular molecular constituents. We might thus imagine the regulatory interactions that occur as development progresses as a chain-like process in which signaling induces expression of new transcriptional regulators, which cause the expression of new signaling functions, crossing in both directions from tissue to tissue. In life, such chains would usually branch, because the interacting spatial domains become subdivided. One element of such a chain might be schematized as in Fig. 3. Note that the essential feature of this abstraction is the same as in Fig. 2A: it 
consists of the repetitive utilization of an elemental regulatory subcircuit, the central components of which are genes encoding regionally expressed transcription factors, controlled by, and controlling spatial signaling interactions. This interpretation is consistent with the general proposal that in morphogenetic regulatory circuits, homeodomain transcription factors, and other classes of regulator with similar functions, may lie both upstream and downstream of intercellular signaling interactions.

\section{NEGATIVE TRANSCRIPTIONAL REGULATORY FUNCTIONS IN THE LOCALIZATION OF MORPHOGENETIC PROGENITOR FIELDS}

The developmental processes on which we have thus far focused illustrate certain regulatory aspects that are apparently quite general. These refer to regulatory control of processes occurring within and between morphogenetic progenitor fields. The remainder of this essay is concerned with the utilization of negative regulatory functions, in setting the spatial boundaries of such morphogenetic fields.

\section{i. Negative spatial control of territorial gene expression in Type 1 embryos}

In Type 1 embryos the earliest progenitor fields consist of sets of lineages, each of which gives rise exclusively to some particular region of the embryo. In the sea urchin embryo the topology is particularly simple, and the polyclonal territories that are the progenitor fields for given morphological structures such as oral and aboral ectoderm, skeleton, or gut, are easily mapped on the spherical late cleavage embryo (Fig. 1A). Recent studies have revealed several examples of negative control of expression of the earliest cohort of territory-specific genes. Thus ectopic spatial expression of fusion constructs often occurs if certain cis/trans regulatory interactions are precluded, either by deletion of target sites or by in vivo competition for these sites. This has been observed, for example, with two different genes normally expressed only in aboral ectoderm, viz. the Spec2a gene, which encodes a $\mathrm{Ca}^{2+}$ binding protein; and the CyIIIa gene, which encodes a territory-specific cytoskeletal actin. In the case of a Spec $2 a \cdot \beta$-gal fusion gene, when a certain region of the regulatory sequence required for proper function was deleted, ectopic expression resulted (Gan et al., 1990). As will be recalled from Fig. 1, the later expression patterns of Endo-16 also clearly imply negative spatial control functions. Thus the initially territory-wide expression of Endo-16 is progressively extinguished in the secondary mesenchyme, the foregut, and the hindgut, up to the proximal and distal boundaries of the midgut or stomach, within which strong Endo-16 expression continues (Fig. 1C; Ransick et al., 1993). For these cases there appear to exist positively acting regulators required for expression, which are apparently not territorially confined (e.g., see Thiebaud et al., 1990), and superimposed on their action are negative spatial controls active only in certain lineages.

In this respect we know the most about the CyIIIa gene. There is interesting evidence for negative control from an interspecific experiment (Franks et al., 1988) in which a CyIIIa.CAT fusion gene, which is always expressed correctly in the species of origin, was injected into eggs of a distant second species. The result is totally promiscuous ectopic expression in the foreign host embryos. Failure of some molecular recognition reactions between the exogenous regulatory sequences and the host regulatory proteins, evidently due to evolutionary sequence divergence, thus reveals that the normal spatial control system is at least in part negative. Ectopic spatial expression can be induced in the species from which the regulatory system derives by in vivo competition. When excess quantities of either of two particular binding sites (out of about ten tested) are introduced together with the CyIIIa.CAT construct, CAT mRNA appears in the wrong territories (Hough-Evans et al., 1990). Competition for the factors binding these two target sites does not depress (and may even increase) the overall level of expression, but causes ectopic expression, in gut, oral ectoderm, and skeletogenic tissues. In contrast, competition for the target sites of a number of other, positively acting factors depresses the level of expression, but leaves unchanged the spatial restriction of expression to the aboral ectoderm that is normally observed (Franks et al., 1990; Hough-Evans et al., 1990).

A similar example is known in the early $C$. elegans embryo. Aamodt et al. (1991) found that a fusion construct under the control of regulatory sequences of the gut-specific ges- 1 esterase gene is expressed ectopically in hypodermis and body wall muscle, or in pharynx, if certain regions of the regulatory domain are deleted. Ectopic expression could also be produced by in vivo competition. At least two

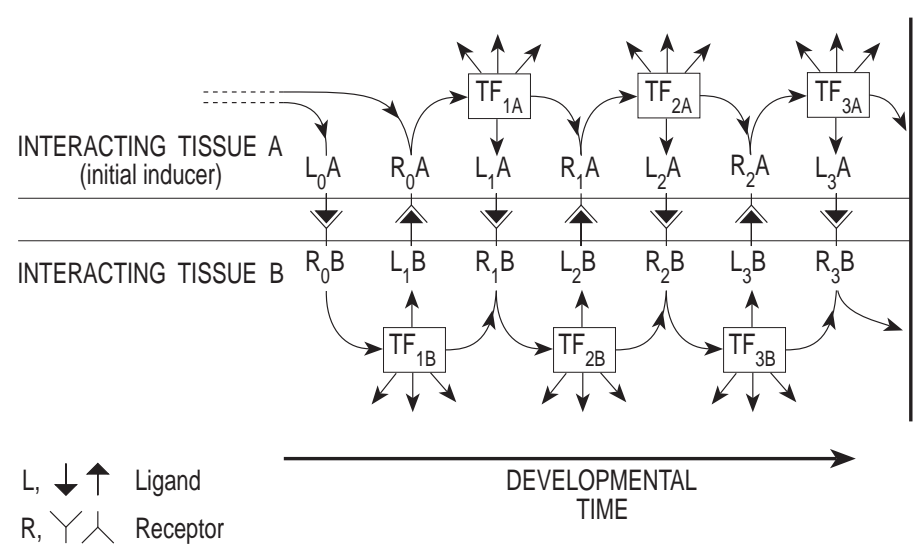

Fig. 3. A chain of interactions between laterally apposed tissues undergoing progressive morphogenetic inductions. In each tissue ( $A$ and $B$ ) a sequence of regulatory changes occurs, controlled by the appearance of new transcription factors (TF) in response to signals from the adjacent tissue. Each new transcription factor (i.e., set of factors) activates batteries of genes (indicated by arrows emanating from the boxes, which represent the nuclear compartments at each stage). The batteries in each case include new signaling systems, here symbolized as new ligands (L), and new receptors $(\mathrm{R})$. 
different lineage-specific repressors plus activators are implied by these results.

In summary, in Type 1 embryos, territories from which only a single morphological structure develops are equivalent to the earliest set of morphogenetic progenitor fields. There is good evidence that molecular control of these specification processes is often at least partly negative. The role of the negative functions is to prevent expression in lineages other than those constituting the appropriate territory. Thus the negative functions are required to define the relevant lineage interfaces as territorial boundaries, and subsequently to subdivide these territories.

\section{ii. Negative spatial control in the Drosophila embryo}

In the later period of precellular development the domains of expression of various zygotic genes encoding key transcriptional regulators become spatially confined. Though the embryo is at this stage syncytial, the mechanism by which regional expression is established is relevant to our subject in two ways: First, it is instructive that this spatial regionalization process generally involves negative regulatory interactions; and second, the molecular nature of this process might indicate the character of intranuclear regulatory processes mediated by signaling in cellular systems that are undergoing regionalization. Regulatory functions required for the specification of many early regional patterns of spatial gene expression have been identified genetically (e.g., Struhl et al., 1992; see reviews of Levine and Harding, 1989; St. Johnston and Nüsslein-Vollhard, 1992), and molecular evidence is now revealing the mechanisms. A general conclusion of basic importance is that multiple interactions of negatively acting transcription factors are directly responsible for setting the spatial limits of expression in the precellular embryo, and that they probably do so by interferring with the cooperative binding, or the function, of positively acting factors which react at nearby cis-target sites. For example, the anterior limit of knirps gene expression is set by five or six interactions with cis-regulatory sites to which the negatively acting hunchback $(h b)$ protein binds, and the posterior limit requires multiple negative interactions at a different cis-regulatory locus with the product of the gap gene tailless (Pankratz et al., 1992). Similarly there are seven sites of $h b$ interaction in the PBX control region of the $U b x$ gene. These negative interactions are required to set the spatial limits of a band of $U b x$ expression, which appears at the syncytial blastoderm stage (Zhang et al., 1991; Qian et al., 1991), and they apparently function antagonistically with a generally distributed positive transcription factor that binds to nearby target sites. The same type of mechanism controls the location of Krüppel $(K r)$ gene expression; here the positive function is carried out by the bicoid $(b c d)$ regulator, and the negative functions by the tailless and knirps factors, the multiple sites for which partially overlap the six $b c d$ sites in the cis control element (Hoch et al., 1992). Multiple negative interactions that interfere in some way with binding or function of positively acting factors also determine the limits and location of pair rule gene expression stripes prior to cellularization (e.g., see Topol et al., 1991; Small et al., 1991; Stanojevic et al., 1991). A spatial expression system that has been examined in particular detail is that responsible for stripe 2 of the evenskipped (eve) pair rule gene. The anterior and posterior limits of stripe 2 are generated respectively by negative interactions of $K r$ and giant $(g t)$ factors that interfere with positive regulators, here $b c d$ and $h b$, within a $c i s$-regulatory element that includes five $b c d$, three $h b$, six $K r$, and three $g t$ binding sites (Small et al., 1991).

These examples all concern expression limits along the $\mathrm{A} / \mathrm{P}$ axis, but the same is true for precellular expression patterns of regulatory genes along the $\mathrm{D} / \mathrm{V}$ axis. Regulation of the prospective mesoderm/neuroectoderm boundaries operates in a fundamentally similar way, though it depends on an entirely different set of transcription factors (Ip et al., 1992). The longitudinal strips of prospective neuroectoderm in the normal embryo occupy arcs of approx. $70^{\circ}$ of lateroventral circumference on either side of the ventral strip of prospective mesoderm. Genes expressed in the mesoderm are positively controlled by the maternal dorsal $(d l)$ transcription factor, which is present in the nuclei at highest concentration mid-ventrally, and at decreasing concentrations more dorsolaterally. The positions of the lateral boundaries of the prospective neuroectoderm with the prospective mesoderm are again negatively regulated, by the snail zinc finger factor, expressed in the mesoderm. Thus in the absence of snail this boundary, as marked by expression of various neuroectoderm marker genes, moves ventrally (Leptin, 1991; Rao et al., 1991; Nambu et al., 1991; Kosman et al., 1991; Kasai et al., 1992). In the regulatory domain that controls expression of the neuroectoderm gene rhomboid are four high affinity dorsal target sites required for expression, and other positive regulators are probably required as well. Closely linked are four sites for the snail repressor (Ip et al., 1992). Similarly, in the relevant region of the cis-regulatory apparatus of the gene singleminded, which is expressed in single cell wide strips that separate the presumptive mesoderm and the presumptive neuroectoderm, there are nine snail target sites that are required to preclude expression more ventrally in the mesoderm territory (Nambu et al., 1991; Kasai et al., 1992).

These, and various other examples that could be adduced (cf. cited reviews) display basic features of the transcriptional regulatory mechanism underlying the spatial confinement of expression domains in the precellular Drosophila embryo. A general aspect of this mechanism is that factor concentration clines are transformed into relatively sharply bounded domains of transcriptional response, by the use of multiple interactions at multiple target sites. In the example of the mesoderm/neuroectoderm boundary there is clear evidence, for both negatively and positively acting factors, that the mechanism by which this occurs depends on cooperative interactions among factors bound at contiguous sites (Jiang and Levine, 1993). In all of these cases, negative regulatory interactions mediated by spatially restricted regulators are used to set spatial boundaries, by interference with the positive functions of more broadly distributed activators.

In most developmental situations boundaries are defined by apposed, communicating cells, and cell signaling is a fundamental feature of the establishment and operation of such boundaries (see discussion of Ingham and Martinez-Arias, 1992). We can easily imagine that the consequence of signaling across the intercellular boundary of a morpho- 
genetic field might result, in the recipient cells, in setting up forms of transcriptional regulatory complexes similar to those controlling expression pattern in the precellular Drosophila embryo, including multiple interactions of positive and negative regulators. I have argued (Davidson, 1991) that in evolutionary terms syncytial Drosophila embryogenesis (or Type III embryogenesis) is a special form derived from the more basic Type I embryonic processes. If this is so, preexisting transcriptional control devices are likely to have been preempted in evolution for the special purposes of the syncytial Type III embryo. Therefore the same principles of molecular regulatory mechanism observed in systems such as those controlling eve stripe 2, or $h b$ or rhomboid expression, also would be expected to apply to systems utilizing only intercellular boundaries; this, however, remains to be seen. Nonetheless, in a general sense the intercellular boundary of a morphogenetic progenitor field can be seen as an interface of regulatory modes that are related in a negative way to one another. For example, the boundaries set up within the sea urchin embryo archenteron separate -/+/- domains of Endol6 expression in foregut, midgut and hindgut, respectively (Fig. 1C). The signaling interactions at such a boundary must either shut off transcriptional activities expressed by the sending cell in the receiving cell across the boundary, activate in the receiving cell a genetic function that is shut off in the sending cell, or both.

There are some pertinent examples in the post-cellularization Drosophila embryo. Intercellular two-way communication occurs across the parasegmental boundaries in the epidermis, for instance. These boundaries form at the interface between cells expressing the wnt family ligand gene $w g$, and cells expressing the engrailed (en) homeodomain transcription factor. These genes are activated independently in response to spatial regulatory signals encoded by pair rule genes prior to cellularization, and both are required subsequently for boundary formation (reviewed by Baumgartner and Noll, 1991; Levine and Harding, 1989; Ingham and Martinez-Arias, 1992). Local concentration differences of the $w g$ ligand are essential for cuticular spatial differentiation, as all the cells are capable of receiving the $w g$ signal if it is expressed ectopically (Noordermeer et al., 1992). In normal development, cells that receive the $w g$ ligand from the apposing cells across the border express en, but do not transcribe the $w g$ gene, while only cells adjacent to those expressing en across the boundary maintain $w g$ expression, and in these cells the en gene is silent. The en expressing cells also generate another negatively acting short-range signal, some aspect of which is probably encoded by the hedgehog $(h h)$ gene. This signal is apparently required for $w g$ expression in the immediately adjacent cells across the boundary; i.e., $w g$ expression is repressed in the more anterior cells further removed from the boundary by a mechanism that the $h h$ function negates (there may be other roles for $h h$ as well, in later stages and other regions of the embryo: see Lee et al., 1992; Mohler and Vani, 1992; review of Ingham and Martinez-Arias, 1992 for evidence, references and arguments).

The location of salivary gland placodes provides another example in which the boundaries of a morphogenetic progenitor field are determined by negative signals across the field boundary (Panzer et al., 1992). Early regulatory interactions define the location in parasegment 2 of a stripe of expression of a homeotic gene (Sexcombs reduced, Scr) which is required for the establishment of the salivary gland anlage. The dorsal border of this field is established later by the domain of expression of the TGF $\beta$ family ligand $d p p$ (or by downstream genes), the effect of which is negative, so that in $d p p$ embryos the field spreads dorsally to form a horseshoe over the whole embryo. The ventral boundary is demarcated by another negative interaction, mediated by the dorsal $(\mathrm{dl})$ regulator, and probably by signaling ligands controlled by $d l$. Another kind of molecular negative regulatory interaction is involved in the spatial specification of the sensilla of the peripheral nervous system. The initial event is establishment of spaced cellular progenitor fields in the expanding imaginal discs within which downstream functions produce neural and accessory cell complexes. Key positive functions required for sensillum formation are encoded by HLH regulators (achaete [as], scute [sc], and daughterless [da]), and the spacing of these primordia depends in part on negative functions encoded by other genes (extramacrochaetae [emc], and hairy; Ellis et al., 1990; Cubas et al., 1991; Garrell and Modolell, 1990). Thus the $a c$ and $s c$ genes are expressed in the proneural territories of the wing disc in a spatial pattern complementary to that of the emc regulator, which thus confines these territories to their appropriate locations (Van Doren et al., 1992). In this case the molecular basis of the negative function is probably formation of an inactive heterodimer including emc, in place of the heterodimers formed by the positive HLH regulators. Intercellular signaling also must occur at the boundaries of the proneural progenitor fields, but their molecular basis is unknown.

The examples mentioned here illustrate the essential engagement of negative regulatory processes in setting the spatial limits of morphogenetic progenitor fields in Type I embryos, in syncytial Drosophila embryo, and in the postcellularization later development of Drosophila. We have seen already, in the discussion of mesoderm specification in Xenopus, similar examples, most notably the mutually negative relation between $X w n t-8$ and goosecoid expression, and between DVR-4 and Xnot expression that delimit boundaries during the process of mesoderm regionalization. Direct molecular evidence that reveals the detailed control mechanisms of genes involved in spatial specification of morphogenetic fields is still uncommon in the higher vertebrate literature, but less direct evidence from a number of cases also suggests negative spatial functions. To cite one example among a great many similar observations, in the chick the Hox 8 homeobox gene is initially expressed uniformly in the posterior unsegmented mesoderm after gastrulation (Yokouchi et al., 1991). As somite formation proceeds its expression is restricted to somatic lateral mesoderm. Then, when the limb buds form, expression of this gene is further restricted, and its transcripts are confined to the anterior proximal region of the bud (Yokouchi et al., 1991; Coelho et al., 1991a; Robert et al., 1991).

Thus, even at the present stage of knowledge, there is evidence for negative regulatory interactions at the boundaries of morphogenetic anlage in representatives of all three major forms of embryogenesis. Such interactions, mediated 
by intercellular signaling, are probably a basic element of the mechanism by which these boundaries are established, and the positions of morphogenetic progenitor fields are set. We may conclude that delimitation of progenitor fields by negative interactions at the boundaries is a general mechanism in embryonic development.

\section{CONCLUDING REMARKS}

Some simple generalizations that can be made are as follows. In the later embryogenesis of all forms, the development of morphogenetic progenitor fields begins with their initial conditional specification through regional signaling processes. Among the key control functions required are those that at the transcriptional level establish the signaling boundaries. In its subsequent development the territory of the progenitor field is typically subdivided, and new internal boundaries are formed. The same general forms of regulatory interactions are likely to be utilized during these regionalization processes, viz. signaling between regions that specifies local expression of transcription factors, which in turn mediate new signaling interactions.

\section{i. The participation of homeodomain regulators}

On current evidence, homeodomain regulators are likely to control conditional regional specifications, though members of other classes of transcriptional regulators no doubt carry out such functions as well. There is striking evidence for correlations between regional combinations of homeobox gene expression, and particular spatial domains and subdomains of various morphogenetic fields (see, e.g., Kessel and Gruss, 1991; Hunt et al., 1991; Robinson et al., 1991; Izpisúa-Belmonte et al., 1991; Dollé et al., 1989; Jegalian and De Robertis, 1992). Homeobox regulators are downstream of signal systems because it is these systems that emplace their transcriptional activity. They may also lie upstream of signal systems, since this could be the means by which they effect the inductive interactions that divide morphogenetic regions.

Many of the vertebrate homeobox genes discussed in this review that are likely to be essential for various morphogenetic processes, are considered 'divergent' with respect to the Antp-Ubx gene clusters of Drosophila. The divergent homeobox genes are not known to exist in clusters of conserved order, as do the Hox gene groups, though they seem to perform comparable, though distinct, morphogenetic functions. Those homeobox genes that occur in evolutionarily conserved complexes are linked by extensive sequence that contains cis-regulatory sites. In Drosophila these complexes may be required only for the maintenance (see e.g., Paro, 1990) of their specific spatial and temporal patterns of expression, while the institution of these patterns could be mediated largely by trans-regulatory interactions that do not depend on the large-scale arrangement of the gene clusters. Or, in both Drosophila and vertebrates, correct transcriptional combinations of homeobox gene expressions in each cell could indeed depend on the largescale spatial organization of regulatory sequence elements conserved in these gene clusters. However, in either case, whatever the functional intranuclear significance of homeobox gene clusters, in cellular developmental systems, the distribution of transcription factors within adjacent cells can only be communicated and controlled from cell to cell by signaling. The arguments reviewed in this paper are focused on the requirement for intercellular signaling in the spatial control of homeobox and other morphogenetic regionalization genes, not withstanding their clustered genomic organization, and their possible intranuclear regulatory interactions.

\section{ii. Network organization of morphogenetic regulatory systems}

On the multicellular scale of morphogenetic progenitor fields, the designs considered here are essentially network, rather than hierarchical designs. Thus the transcriptional status of given cells determines not only the constitution of the batteries of genes they express at each stage of the process, but also the transcriptional status, and hence the molecular activities, of adjacent cells. Furthermore, within each cell different combinations of transcriptional regulators are utilized in different genes in overlapping patterns, and the activity of some of these regulators depends in turn on intercell signaling. These features suggest that many of the signal systems and transcriptional regulators involved in intermediate morphogenetic functions are probably subject to control from many directions, rather than only from higher level 'master genes' in a linear hierarchical sequence. Thus experiments in which expression of genes encoding intermediate morphogenetic functions is perturbed are not obviously to be expected to yield simple, linearly interpretable phenotypes. This is of course particularly likely to be true of experimentally forced, ectopic overexpression of transcriptional regulators that lie in the midst of such networks. Exceptions would include cases in which initial or terminal functions are affected, or in which the morphogenetic process is much simpler than most of those considered here.

\section{iii. A 'regionalization' regulatory module}

There is a striking simplicity that emerges in the regulatory processes that underlie the partitioning of morphological space. The same relatively small set of ligands, receptors, other intercellular signaling effector molecules, and the same transcriptional regulators, are utilized in successive stages of a given morphogenetic process, and also in many different independent morphogenetic processes. The argument developed here is that each step in the development of morphogenetic progenitor fields requires the same forms of basic regulatory functions. These are the spatial signaling activities by which the field is initially conditionally established, its boundaries generated and maintained, and the properties of its cells specified by unique combinations of transcription factors; and the same forms of control functions are repetitively required as the field is subdivided, new boundaries are established, and new subpatterns of transcription factor expression are executed. The diversity we see is in the complexity of the batteries of downstream effector genes, that encode diverse differentiation functions (including those that produce diverse self-assembling threedimensional structures, that look different, both within and outside cells). The repetitive use of the same subcircuit reg- 
ulatory elements implies that the transcription regulators actually involved in spatial control of morphogenetic fields are themselves controlled by similar cis interactions. That is, their expression may depend on combinations drawn from only a small set of modifiable transcription factors. Furthermore, the signaling apparatuses which these genes control downstream may be similarly wired, so that they in turn respond to members of a relatively small set of different homeodomain (and other) transcription factors, in different combinations. These arguments, in short, predict the existence and the general nature of a basic modular regulatory circuit feature, essentially that shown in Fig. 2B. Such [signal-to transcription factor-to signal] circuit subelements, and the genes and gene products they require, have perhaps been used throughout metazoan evolution for developmental regionalization, i.e., for the construction and subdivision of morphogenetic progenitor fields.

I am immeasurably indebted to many colleagues, for their thoughtfulness, their wisdom and their perspicacity in guiding me to improvements of drafts of this manuscript. For their interest and extensive efforts, and the marvelous discussions this project occasioned, I particularly wish to thank Richard Axel, of the HHMI at Columbia University; Marianne Bronner-Fraser, of UC Irvine; Roy Britten of Caltech; Andrew Cameron of Caltech; Scott Fraser of Caltech; Mike Levine of UC San Diego; David Kimelman of the University of Washington; Ellen Rothenberg of Caltech; and Paul Sternberg of Caltech. Research from this laboratory was supported by an NIH grant (HD-05753).

\section{REFERENCES}

Aamodt, E. J., Chung, M. A. and McGhee, J. D. (1991). Spatial control of gut-specific gene expression during Caenorhabditis elegans development. Science 251, 579-582.

Amaya E., Musci, T. J. and Kirschner, M. W. (1991). Expression of a dominant negative mutant of the FGF receptor disrupts mesoderm formation in Xenopus embryos. Cell 66, 257-270.

Asashima, M., Nakano, H., Uchiyama, H., Sugino, H., Nakamura, T., Eto, Y., Ejima, D., Nishimatsu, S.-I., Ueno, N. and Kinoshita, K. (1991). Presence of activin (erythroid differentiation factor) in unfertilized eggs and blastulae of Xenopus laevis. Proc. Natl. Acad. Sci. USA 88, 6511-6514.

Baumgartner, S. and Noll, M. (1991). Network of interactions among pairrule genes regulating paired expression during primordial segmentation of Drosophila. Mech. Dev. 33, 1-18.

Blum, M., Gaunt, S. J., Cho, K. W. Y., Steinbeiser, H., Blumberg, B., Bittner, D. and De Robertis, E. M. (1992). Gastrulation in the mouse: The role of the homeobox gene goosecoid. Cell 69, 1097-1106.

Blumburg, B., Wright, C. V. E., De Robertis, E. M. and Cho, K. W. Y. (1991). Organizer-specific homeobox genes in Xenopus laevis embryos. Science 253, 194-196.

Boterenbrod, E. C. and Nieuwkoop, P. D. (1973). The formation of the mesoderm in urodelean amphibians. V. Its regional induction by the endoderm. Wilhelm Roux' Archiv. Dev. Biol. 173, 319-332.

Bowerman, B., Eaton, B. A. and Priess, J. R. (1992). skn-1, a maternally expressed gene required to specify the fate of ventral blastomeres in the early C. elegans embryo. Cell 68, 1061-1075.

Cameron, R. A. and Davidson, E. H. (1991). Cell type specification during sea urchin development. Trends Genet. 7, 212-218.

Cameron, R. A., Hough-Evans, B. R., Britten, R. J. and Davidson, E. H. (1987). Lineage and fate of each blastomere of the eight-cell sea urchin embryo. Genes Dev. 1, 75-85.

Cameron, R. A., Fraser, S. E., Britten, R. J. and Davidson, E. H. (1991). Macromere cell fates during sea urchin development. Development 113, 1085-1092.

Cho, K. W. Y. and De Robertis, E. M. (1990). Differential activation of
Xenopus homeobox genes by mesoderm-inducing growth factors and retinoic acid. Genes Dev. 4, 1910-1916.

Cho, K. W. Y., Blumberg, B., Steinbeisser, H. and De Robertis, E. M. (1991a). Molecular nature of Spemann's organizer: The role of the Xenopus homeobox gene goosecoid. Cell 67, 1111-1120.

Cho, K. W. Y., Morita, E. A., Wright, C. V. E. and De Robertis, E. M. (1991b). Overexpression of a homeodomain protein conferes axisforming activity to uncommitted Xenopus embryonic cells. Cell 65, 5564.

Christian, J. L. and Moon, R. T. (1993). Interactions between the Xwnt-8 and Spemann organizer signalling pathways generate dorsoventral pattern in the embryonic mesoderm of Xenopus. Genes Dev. 7, 13-28.

Christian, J. L., McMahon, J. A., McMahon, A. P. and Moon, R. T. (1991). Xwnt-8, a Xenopus Wnt-1/int-1-related gene responsive to mesoderm-inducing factors, may play a role in ventral mesodermal patterning during embryogenesis. Development 111, 1045-1055.

Christian, J. L., Olson, D. J. and Moon, R. T. (1992). Xwnt-8 modifies the character of mesoderm induced by bFGF in isolated Xenopus ectoderm. EMBO J. 11, 33-41.

Coelho, C. N. D., Sumoy, L., Rodgers, B. J., Davidson, D. R., Hill, R. E., Upholt, W. B. and Kosher, R. A. (1991a). Expression of the chicken homeobox-containing gene GHox-8 during embryonic chick limb development. Mech. Dev. 34, 143-154.

Coelho, C. N. D., Krabbenhoft, K. M., Upholt, W. B., Fallon, J. F. and Kosher, R. A. (1991b). Altered expression of the chicken homeoboxcontaining gene GHox-7 and GHox-8 in the limb buds of limbless mutant chick embryos. Development 113, 1487-1493.

Coelho, C. N. D., Sumoy, L., Kosher, R. A. and Upholt, W. B. (1992a). GHox-7: A chicken homeobox-containing gene expressed in a fashion consistent with a role in patterning events during embryonic chick limb development. Differentiation 49, 85-92.

Coehlo, C. N. D., Upholt, W. B. and Kosher, R. A. (1992b). Role of the chicken homeobox-containing genes GHox-4.6 and GHox-8 in the specification of positional identities during the development of normal and polydactylous chick limb buds. Development 115, 629-637.

Coffman, J. A. and McClay, D. R. (1990). A hyaline layer protein that becomes localized to the oral ectoderm and foregut of sea urchin embryos. Dev. Biol. 140, 93-104.

Cooke, J. (1989). Mesoderm-inducing factors and Spemann's organizer phenomenon in amphibian development. Development 107, 229-241.

Cox, K. H., Angerer, L. M., Lee, J. J., Davidson, E. H. and Angerer, R. C. (1986). Cell lineage-specific programs of expression of multiple actin genes during sea urchin embryogenesis. J. Mol. Biol. 188, 159-172.

Cubas, P., De Celis, J.-F., Campuzano, S. and Modolell, J. (1991). Proneural clusters of achaete-scute expression and the generation of sensory organs in the Drosophila imaginal wing disc. Genes Dev. 5, 9961008.

Cunliff, V. and Smith, J. C. (1992). Ectopic mesoderm formation in Xenopus embryos caused by widespread expression of a Brachyury homologue. Nature 358, 427-430.

Dale, L., Smith, J. C. and Slack, J. M. W. (1985). Mesoderm induction in Xenopus laevis: A quantitative study using a cell lineage label and tissuespecific antibodies. J. Embryol. exp. Morph. 89, 289-312.

Dale, L., Howes, G., Price, B. M. J. and Smith, J. C. (1992). Bone morphogenetic protein 4: A ventralizing factor in early Xenopus development. Development 115, 573-585.

Davidson, D. R., Crawley, A., Hill, R. E. and Tickle, C. (1991). Positiondependent expression of two related homeobox genes in developing vertebrate limbs. Nature 352, 429-431.

Davidson, E. H. (1986). Gene Activity in Early Development, Third Edition. Orlando, Florida: Academic Press.

Davidson, E. H. (1989). Lineage-specific gene expression and the regulative capacities of the sea urchin embryo: a proposed mechanism. Development 105, 421-445.

Davidson, E. H. (1990). How embryos work: a comparative view of diverse modes of cell fate specification. Development 108, 365-389.

Davidson, E. H. (1991). Spatial mechanisms of gene regulation in metazoan embryos. Development 113, 1-26.

De Robertis, E. M., Morita, E. A. and Cho, K. W. Y. (1991). Gradient fields and homeobox genes. Development 112, 669-678.

Detrick, R. J., Dickey, D. and Kintner, C. R. (1990). The effects of Ncadherin misexpression on morphogenesis in Xenopus embryos. Neuron 4, 493-506.

Dirksen, M. L. and Jamrich, M. (1992). A novel, activin-inducible, 
blastopore lip-specific gene of Xenopus laevis contains a fork head DNAbinding domain. Genes Dev. 6, 599-608.

Dixon, J. E. and Kintner, C. R. (1989). Cellular contacts required for neural induction in Xenopus embryos: evidence for two signals. Development 106, 749-757.

Dollé, P., Izpisúa-Belmonte, J.-C., Falkenstein, H., Renucci, A. and Duboule, D. (1989). Coordinate expression of the murine Hox-5 complex homeobox-containing genes during limb pattern formation. Nature $\mathbf{3 4 2}$, 767-772.

Doniach, T., Phillips, C. R. and Gerhart, J. C. (1992). Planar induction of anteroposterior pattern in the developing central nervous system of Xenopus laevis. Science 257, 542-545.

Driesch, H. (1905). Die entwickelungsphysiologie von 1902-1905. Ergeb. d. Anat. u. Entwick, Bd. 14.

Ellis, H. M., Spann, D. R. and Posakony, J. W. (1990). Extramacrochaetae, a negative regulator of sensory organ development in Drosophila, defines a new class of helix-loop-helix proteins. Cell 61, 2738.

Epstein, D. J., Vekemans, M. and Gros, P. (1991). splotch $\left(S p^{2 H}\right)$, a mutation affecting development of the mouse neural tube, shows a deletion within the paired homeodomain of Pax-3. Cell 67, 767-774.

Ettensohn, C. A. (1984). Primary invagination of the vegetal plate during sea urchin gastrulation. Amer. Zool. 24, 571-588.

Ettensohn, C. A. (1992). Cell interactions and mesodermal cell fates in the sea urchin embryo. Development Supplement 1992, 43-51.

Ettensohn, C. A. and Ingersoll, E. P. (1992). Morphogenesis of the sea urchin embryo. In Morphogenesis, Ch. 7 (ed., E. F. Rossomando and S. Alexander), pp. 189-261. New York: Marcel Dekker, Inc.

Franks, R. R., Hough-Evans, B. R., Britten, R. J. and Davidson, E. H. (1988). Spatially deranged though temporally correct expression of a Strongylocentrotus purpuratus actin gene fusion in transgenic embryos of a different sea urchin family. Genes Dev. 1, 1-12.

Franks, R. R., Anderson, R., Moore, J. G., Hough-Evans, B. R., Britten, R. J. and Davidson, E. H. (1990). Competitive titration in living sea urchin embryos of regulatory factors required for expression of the CyIIIa actin gene. Development 110, 31-40.

Fujimori, T., Miyatani, S. and Takeichi, M. (1990). Ectopic expression of $\mathrm{N}$-cadherin perturbs histogenesis in Xenopus embryos. Development 110, 97-104.

Gallagher, B. C., Hainski, A. M. and Moody, S. A. (1991). Autonomous differentiation of dorsal axial structures from an animal cap cleavage stage blastomere in Xenopus. Development 112, 1103-1114.

Gan, L., Wessel, G. M. and Klein, W. H. (1990). Regulatory elements from the related spec genes Strongylocentrotus purpuratus yield different spatial patterns with a lacZ reporter gene. Dev. Biol. 142, 346-359.

Garrell, J. and Modolell, J. (1990). The Drosophila extramacrochaetae locus, an antagonist of proneural genes that, like these genes, encodes a helix-loop-helix protein. Cell 61, 39-48.

Gerhart, J., Danilchik, M., Doniach, T., Roberts, S., Rowning, B. and Stewart, R. (1989). Cortical rotation of the Xenopus egg: consequences for the anteroposterior pattern of embryonic dorsal development. Development Supplement 1989, 37-51.

Gerhart, J., Doniach, T. and Stewart, R. (1991). Organizing the Xenopus organizer. In Gastrulation (ed. R. Keller, W. H. Clark, Jr. and F. Griffin), pp. 57-76, New York: Plenum Press.

Ghysen, A. and Dambly-Chandière, C. (1989). Genesis of the Drosophila peripheral nervous system. Trends Genet. 5, 251-255.

Gimlich, R. L. (1985). Cytoplasmic localization and chordamesoderm induction in the frog embryo. J. Embryol. exp. Morph. 89, 89-111.

Gimlich, R. L. (1986). Acquisition of developmental autonomy in the equatorial region of the Xenopus embryo. Dev. Biol. 115, 340-352.

Gimlich, R. and Gerhart, J. (1984). Early cellular interactions promote embryonic axis formation in Xenopus. Dev. Biol. 104, 117-130.

Goldstein, B. (1992). Induction of gut in Caenorhabditis elegans embryos. Nature 357, 255-257.

Gould, A. P. and White, R. A. H. (1992). Connectin, a target of homeotic gene control in Drosophila. Development 116, 1163-1174.

Green, J. B. A. and Smith, J. C. (1990). Graded changes in dose of a Xenopus activin A homologue elicit stepwise transitions in embryonic cell fate. Nature 347, 391-394.

Green, J. B. A., Howes, G., Symes, K., Cooke, J. and Smith, J. C. (1990). The biological effects of XTC-MIF: quantitative comparison with Xenopus bFGF. Development 108, 173-183.

Green, J. B. A., New, H. V. and Smith, J. C. (1992). Responses of embryonic Xenopus cells to activin and FGF are separated by multiple dose thresholds and correspond to distinct axes of the mesoderm. Cell 71, 731-739.

Gruss, P. and Walther, C. (1992). Pax in development. Cell 69, 719-722.

Hardin, J. (1989). Local shifts in position and polarized motility drive cell rearrangement during sea urchin gastrulation. Dev. Biol. 136, 430-445.

Hardin, J. D. and Cheng, L. Y. (1986). The mechanisms and mechanics of archenteron elongation during sea urchin gastrulation. Dev. Biol. 115, 490-501.

Hardin, J. and McClay, D. R. (1990). Target recognition by the archenteron during sea urchin gastrulation. Dev. Biol. 142, 86-102.

Hardin, J., Coffman, J. A., Black, S. D. and McClay, D. R. (1992). Commitment along the dorsoventral axis of the sea urchin embryo is altered in response to $\mathrm{NiCl}_{2}$. Development 116, 671-685.

Hemmati-Brivanlou, A. and Melton, D. A. (1992). A truncated activin receptor inhibits mesoderm induction and formation of axial structures in Xenopus embryos. Nature 359, 609-614.

Henry, J. J., Amemiya, S., Wray, G. A. and Raff, R. A. (1989). Early inductive interaction are involved in restricting cell fates of mesomeres in sea urchin embryos. Dev. Biol. 136, 140-153.

Herrmann, B. G., Labeit, S., Poustka, A., King, T. R. and Lehrach, H. (1990). Cloning of T gene required in mesoderm formatin in the mouse. Nature 343, 617-622.

Hill, R. E., Favor, J., Hogan, B. L. M., Ton, C. C. T., Sauders, G. F., Hanson, I. M., Prosser, J., Jordan, T., Hastie, N. D. and Van Heyningen, V. (1991). Mouse small eye results from mutations in a paired-like homeobox-containing gene. Nature 354, 522-525.

Hirai, Y., Nose, A., Kobayashi, S. and Takeichi, M. (1989). Expression and role of E- and P-cadherin adhesion molecules in embryonic histogenesis (I. Lung epithelial morphogenesis). Development 105, 263270.

Hoch, M., Gerwin, N., Taubert, H. and Jäckle, H. (1992). Competition for overlapping sites in the regulatory region of the Drosophila gene Krupple. Science 256, 94-97.

Hopwood, N. D., Pluck, A. and Gurdon, J. B. (1989). MyoD expression in the forming somites in an early response to mesoderm induction in Xenopus embryos. EMBO J. 8, 3409-3417.

Hörstadius, S. (1973). Experimental Embryology of Echinoderms. London: Clarendon Press.

Hough-Evans, B. R., Franks, R. R., Zeller, R. W., Britten, R. J. and Davidson, E. H. (1990). Negative spatial regulation of the lineage specific CyIIIa actin gene in the sea urchin embryo. Development 110, 4150

Hunt, P., Gulisano, M., Cook, M., Sham, M.-H., Faiella, A., Wilkinson, D., Boncinelli, E. and Krumlauf, R. (1991). A distinct Hox code for the branchial region of the vertebrate head. Nature 353, 861-864.

Huxley, J. S. and de Beer, G. R. (1934). The Elements of Experimental Embryology. London: Cambridge University Press.

Hynes, R. O. and Lander, A. D. (1992). Contact and adhesive specificities in the associations, migrations, and targeting of cells and axons. Cell $\mathbf{6 8}$, 303-322.

Immerglück, K., Lawrence, P. A. and Bienz, M. (1990). Induction across germ layers in Drosophila mediated by a genetic cascade. Cell 62, 261268.

Ingham, P. W. and Martinez-Arias, A. (1992). Boundaries and fields in early embryos. Cell 68, 221-235.

Ip, Y. T., Park, R. E., Kosman, D., Bier, E., and Levine, M. (1992). The dorsal gradient morphogen regulates stripes of rhomboid expression in the presumptive neuroectoderm of the Drosophila embryo. Genes Dev. 6 , 1728-1739.

Isaac, H. V., Tannahill, D. and Slack, J. M. W. (1992). Expression of a novel FGF in the Xenopus embryo. A new candidate inducing factor for mesoderm formation and anteroposterior specification. Development 114 , 711-720

Izpisúa-Belmonte, J.-C. and Duboule, D. (1992). Homeobox genes and pattern formation in the vertebrate limb. Dev. Biol. 152, 26-36.

Izpisúa-Belmonte, J.-C., Tickle, C., Dollé, P., Wolpert, L. and Duboule, D. (1991). Expression of the homeobox Hox-4 genes and the specification of position in chick wing development. Nature 350, 585-589.

Izpisúa-Belmonte, J.-C., Brown, J. M., Duboule, D. and Tickle, C. (1992). Expression of Hox-4 genes in the chick wing links pattern formation to the epithelial-mesenchymal interactions that mediate growth. EMBO J. 11, 1451-1457.

Jegalian, B. G. and De Robertis, E. M. (1992). Homeotic transformation 
in the mouse induced by overexpression of a human Hox3.3 transgene. Cell 71, 901-910.

Jessell, T. M. and Melton, D. A. (1992). Diffusible factors in vertebrate embryonic induction. Cell 68, 257-270.

Jiang, J. and Levine, M. (1993). Binding affinities and cooperative interactions with bHLH activators delimit threshold responses to the dorsal gradient morphogen. Cell 72, 741-752.

Jones, C. M., Lyons, K. M., Lapan, P. M., Wright, C. V. E. and Hogan, B. L. M. (1992a). DVR-4 (bone morphogenetic protein-4) as a posteriorventralizing factor in Xenopus mesoderm induction. Development 115, 639-647.

Jones, F. S., Prediger, E. A., Bittner, D. A., De Robertis, E. M. and Edelman, G. M. (1992b). Cell adhesion molecules as targets for Hox genes: Neural cell adhesion molecule promoter activity is modulated by cotransfection with Hox-2.5 and -2.4. Proc. Natl. Acad. Sci. USA 89, 2086-2990.

Jones, F. S., Chalepakis, G., Gruss, P. and Edelman, G. M. (1992c). Activation of the cytotactin promoter by the homeobox-containing gene Evx-1. Proc. Natl. Acad. Sci. USA 89, 2091-2095.

Kageura, H. (1990). Spatial distribution of the capacity to initiate a secondary embryo in the 32-cell embryo of Xenopus laevis. Dev. Biol. 142, 432-438.

Kaneda, T. (1981). Studies on the formation and state of determination of the trunk organizer in the newt, Cynops pyrrhogaster. III. Tangential induction in the dorsal marginal zone. Dev.Growth Diff. 23, 553-564.

Kaneda, T. and Suzuki, A. S. (1983). Studies on the formation and state of determination of the trunk organizer in the newt, Cynops. pyrrhogaster. IV. The association of the neural-inducing activity with the mesodermization of the trunk organizer. Roux's Arch. Dev. Biol. 192, 812.

Kasai, Y., Nambu, J. R., Lieberman, P. M. and Crews, S. T. (1992). Dorsal-ventral patterning in Drosophila: DNA binding of snail protein to the single-minded gene. Proc. Natl. Acad. Sci. USA 89, 3414-3418.

Keller, R. E. (1976). Vital dye mapping of the gastrula and neurula of Xenopus laevis. II. Prospective areas and morphogenetic movements of the deep layer. Dev. Biol. 51, 118-137.

Keller, R., Shih, J. and Sater, A. (1992a). The cellular basis of the convergence and extension of the Xenopus neural plate. Devel. Dynamics 193, 199-217

Keller, R., Shih, J., Sater, A. K. and Morena, C. (1992b). Planar induction of convergence and extension of the neural plate by the organizer of Xenopus. Devel. Dynamics 193, 218-234.

Kessel, M. and Gruss, P. (1991). Homeotic transformations of murine vertebrae and concomitant alteration of Hox Codes induced by retinoic acid. Cell 67, 89-104.

Khaner, O. and Wilt, F. (1991). Interactions of different vegetal cells with mesomeres during early stages of sea urchin development. Development 112, 881-890

Kimelman, D. and Kirschner, M. (1987). Synergistic induction of mesoderm by FGF and TGF-beta and the indentification of an mRNA coding for FGF in the early Xenopus embryo. Cell 51, 869-877.

Kimelman, D. and Maas, A. (1992). Induction of dorsal and ventral mesoderm by ectopically expressed Xenopus basic fibroblast growth factor. Development 114, 261-269.

Kimelman, D., Abraham, J. A., Haaparanta, T., Palisi, T. M. and Kirschner, M. W. (1988). The presence of fibroblast growth factor in the frog egg: its role as a natural mesoderm inducer. Science 242, 1053-1056.

Kimelman, D., Christian, J. L. and Moon, R. T. (1992). Synergistic principles of development: Overlapping patterning system in Xenopus mesoderm induction. Development 116, 1-9.

Knöchel, S., Lef, J., Clement, J., Klocke, B., Hille, S., Köster, M. and Knöchel, W. (1992). Activin A induced expression of a fork head related gene in posterior chordamesoderm (notochord) of Xenopus laevis embryos. Mech. Dev. 38, 157-165.

Kosman, D., Ip, Y. T., Levine, M. and Arora, K. (1991). Establishment of the mesoderm-neuroectoderm boundary in the Drosophila embryo. Science 254, 118-122.

Lallier R. (1964). Biochemical aspects of animalization and vegetalization in the sea urchin embryo. Adv. Morphogen. 3, 147-196.

Langston, A. W. and Gudas, L. J. (1992). Identification of a retinoic acid responsive enhancer $3^{\prime}$ of the murine homeobox gene Hox-1.6. Mech. Dev. 38, 217-228.

Lennarz, W. J. (1983). Glycoprotein synthesis and embryonic development. CRC Crit. Rev. Biochem. 14, 257-271.
Lee, J. J., Shott, R. J., Rose III, S. J., Thomas, T. L., Britten, R. J. and Davidson, E. H. (1984). Sea urchin actin gene subtypes: Gene number, linkage, and evolution. J. Mol. Biol. 172, 149-176.

Lee, J. J., von Kessler, D. P., Parks, S. and Beachy, P. A. (1992). Secretion and localized transcription suggest a role in positional signaling for products of the segmentation gene hedgehog. Cell 71, 33-50.

Leptin, M. (1991). Twist and snail as positive and negative regulators during Drosophila mesoderm development. Genes Dev. 5, 1568-1576.

Levine, M. S. and Harding, K. W. (1989). Drosophila: The zygotic contribution. In Genes and Embryos, Ch. 2, pp. 39-94, (ed. D. M. Glover and B. D. Hames). New York: IRL Press.

Livingston, B. T. and Wilt, F. H. (1989). Lithium evokes expression of vegetal-specific molecules in the animal blastomeres of sea urchin embryos. Proc. Natl. Acad. Sci. USA 86, 3669-3673.

Livingston, B. T. and Wilt, F. H. (1992). Phorbol esters alter cell fate during development of sea urchin embryos. J. Cell Biol. 119, 1641-1648.

Lyons, G. E., Houzelstein, D., Sassoon, D., Robert, B. and Buckingham, M. E. (1992). Multiple sites of Hox-7 expression during mouse embryogenesis: Comparison with retinoic acid receptor mRNA localization. Mol. Reprod. Dev. 32, 303-314.

Mackenzie, A., Ferguson, M. W. J. and Sharpe, P. T. (1991). Hox-7 expression during murine craniofacial development. Development 113, 601-611.

Mathews, L. S., Vale, W. W. and Kintner, C. R. (1992). Cloning of a second type of activin receptor and functional characterization in Xenopus embryos. Science 255, 1702-1705.

McClay, D., Cannon, G., Wessel, G., Fink, R. and Marchase, R. (1983). Patterns of antigenic expression in early sea urchin development. In Time, Space and Pattern in Embryonic Development (ed. W. R. Jeffery and R. A. Raff), pp. 157-170, New York: Alan R. Liss, Inc.

McGinnis, W. and Krumlauf, R. (1992). Homeobox genes and axial patterning. Cell 68, 283-302.

Meinhardt, H. (1982). Models of Biological Pattern Formation. London: Academic Press.

Moase, C. E. and Trasler, D. G. (1991). N-CAM alterations in splotch neural tube defect mouse embryos. Development 113, 1049-1058.

Mohler, J. and Vani, K. (1992). Molecular organization and embryonic expression of the hedgehog gene involved in cell-cell communication in segmental patterning of Drosophila. Development 115, 957-971.

Molven, A., Wright, C. V. E., Bremiller, R., De Robertis, E. M. and Kimmel, C. B. (1990). Expression of a homeobox gene product in normal and mutant zebrafish embryos: Evolution of the tetrapod body plan. Development 109, 279-288.

Moon, R. T. (1993). In pursuit of the functions of the Wnt family of developmental regulators: Insights from Xenopus laevis. BioEssays 15, 91-97.

Moscoso del Prado, J. and Garcia-Bellido, A. (1984). Cell interactions in the generation of chaetae pattern in Drosophila. Roux's Arch. Dev. Biol. 193, 246-251.

Muneoka, K. and Sassoon, D. (1992). Molecular aspects of regeneration in developing vertebrate limbs. Dev. Biol. 152, 37-49.

Nambu, J. R., Lewis, J. O., Wharton, K. A., Jr. and Crews, S. T. (1991). The Drosophila single-minded gene encodes a helix-loop-helix protein that acts as a master regulator of CNS midline development. Cell $\mathbf{6 7}$ $1157-1167$.

Niehrs, C. and De Robertis, E. M. (1991). Ectopic expression of a homeobox gene changes cell fate in Xenopus embryos in a positionspecific manner. EMBO J. 10, 3621-3629.

Niehrs, C., Keller, R., Cho, K. W. Y. and De Robertis, E. M. (1993). The homeobox gene goosecoid controls cell migration in Xenopus embryos. Cell 72, 491-503.

Nieuwkoop, P. D. (1977). Origin and establishment of embryonic polar axes in amphibian development. Curr. Top. Dev. Biol. 11, 115-132.

Nocente-McGrath, C., Brenner, C. A. and Ernst, S. G. (1989). Endo16, a lineage-specific protein of the sea urchin embryo, is first expressed just prior to gastrulation. Dev. Biol. 136, 264-272.

Noordermeer, J., Johnston, P., Rijsewijk, F., Nusse, R. and Lawrence, P. A. (1992). The consequences of ubiquitous expression of the wingless gene in the Drosophila embryo. Development 116, 711-719.

Oliver, G., Wright, C. V. E., Hardwicke, J. and De Robertis, E. M. (1988). A gradient of homeodomain protein in developing forelimbs of Xenopus and mouse embryos. Cell 55, 1017-1024.

Oliver, G., De Robertis, E. M., Wolpert, L. and Tickle, C. (1990). Expression of a homeobox gene in the chick wing bud following 
application of retinoic acid and grafts of polarizing region tissue. $E M B O$ J. 9, 3093-3099.

Panganiban, G. E. F., Reuter, R., Scott, M. P. and Hoffman, F. M. (1990). A Drosophila growth factor homolog, decapentaplegic, regulates homeotic gene expression within and across germ layers during midgut morphogenesis. Development 110, 1041-1050.

Pankratz, M. J., Busch, M., Hoch, M., Seifert, E. and Jäckle, H. (1992). Spatial control of the gap gene knirps in the Drosophila embryo by posterior morphogen system. Science 255, 986-989.

Panzer, S., Weigel, D. and Beckendorf, S. K. (1992). Organogenesis in Drosophila melanogaster: embryonic salivary gland determination is controlled by homeotic and dorsoventral patterning genes. Development 114, 49-57.

Paro, R. (1990). Imprinting a determined state into the chromatin of Drosophila. Trends Genet. 6, 416-421.

Pehrson, J. R. and Cohen, L. H. (1986). The fate of the small micromeres in sea urchin development. Dev. Biol. 113, 522-526.

Popperl, H. and Featherstone, M. S. (1993). Identification of a retinoic acid response element upstream of the murine Hox-4.2 gene. Mol. Cell. Biol. 13, 257-265.

Priess, J. R. and Thomson, J. N. (1987). Cellular interactions in early $C$. elegans embryos. Cell 48, 241-250.

Qian, S., Capovilla, M. and Pirrotta, V. (1991). The $b x$ region enhancer, a distant cis-control element of the Drosophila Ubx gene and its regulation by hunchback and other segmentation genes. EMBO J. 10, 1415-1425.

Ransick, A. and Davidson, E. H. (1993). A complete second gut induced by transplanted micromeres in the sea urchin embryo. Science 259, 11341138.

Ransick, A., Ernst, S., Britten, R. J. and Davidson, E. H. (1993). Whole mount in situ hybridization shows Endo-16 to be a marker for the vegetal plate territory. Mech. Dev. (in press).

Rao, Y., Vaessin, H., Jan, L. Y. and Jan. Y.-N. (1991). Neuroectoderm in Drosophila embryos is dependent on the mesoderm for positioning but not for formation. Genes Dev. 5, 1577-1588.

Reuter, R., Panganiban, G. E. F., Hoffman, F. M. and Scott, M. P. (1990). Homeotic genes regulate the spatial expression of putative growth factors in the visceral mesoderm of Drosophila embryos. Development 110, 1031-1040.

Robert, B., Lyons, G., Simandl, B. K., Kuroiwa, A. and Buckingham, M. (1991). The apical ectodermal ridge regulates Hox-7 and Hox-8 gene expression in developing chick limb buds. Genes Dev. 5, 2363-2374.

Robinson, G. W., Wray, S. and Mahon, K. A. (1991). Spatially restricted expression of a member of a new family of murine distal-less homeobox genes in the developing forebrain. The New Biologist 3, 1183-1194.

Ros, M. A., Lyons, G., Kosher, R. A., Upholt, W. B., Coelho, C. N. D. and Fallon, J. F. (1992). Apical ridge dependent and independent mesodermal domains of GHox-7 and GHox-8 expression in chick limb buds. Development 116, 811-818.

Ruiz i Altaba, A. (1992). Planar and vertical signals in the induction and patterning of the Xenopus nervous system. Development 115, 67-80.

Ruiz i Altaba, A. and Jessell, T. (1991). Retinoic acid modifies mesodermal patterning in early Xenopus embryos. Genes Dev. 5, 175187.

Ruiz i Altaba, A. and Jessell, T. M. (1992). Pintallavis, a gene expressed in the organizer and midline cells of frog embryos: involvement in the development of the neural axis. Development 116, 81-93.

Ruiz i Altaba, A. and Melton, D. A. (1989a). Involvement of the Xenopus homeobox gene Xhox 3 in pattern formation along the anterior-posterior axis. Cell 57, 317-326.

Ruiz i Altaba, A. and Melton, D. A. (1989b). Interaction between peptide growth factors and homeobox genes in the establishment of anteroposterior polarity in frog embryos. Nature 341, 33-38.

Schanbel, R. (1991). Cellular interactions involved in the determination of the early C. elegans embryo. Mech. Dev. 34, 85-100.

Shih, J., and Keller, R. (1992a). The epithelium of the dorsal marginal zone of Xenopus has organizer properties. Development 116, 887-899.

Shih, J. and Keller, R. (1992b). Patterns of cell motility in the organizer and dorsal mesoderm of Xenopus laevis. Development 116, 915-930.

Shimamura, K. and Takeichi, M. (1992). Local and transient expression of E-cadherin involved in mouse embryonic brain morphogenesis. Development 116, 1011-1019.

Simeone, A., Acampora, D., Acrioni, L., Andrews, P. M., Boncinelli, E. and Mavilio, F. (1990). Sequential activation of HOX2 homeobox genes by retinoic acid in human embryonal carcinoma cells. Nature 346, $763-$ 766.

Simeone, A., Acampora, D., Nigro, V., Faiella, A., D'Esposito, M., Stornaiurolo, A., Mavilio, F. and Boncinelli, E. (1991). Differential regulation by retinoic acid of the homeobox genes of the four HOX loci in human embryonal carcinoma cells. Mech. Dev. 33, 215-228.

Sive, H. L., Draper, B. W., Harland, R. M. and Weintraub, H. (1990). Identification of a retinoic acid-sensitive period during primary axis formation in Xenopus laevis. Genes Dev. 4, 932-942.

Sive, H. L. and Cheng, P. F. (1991). Retinoic acid perturbs the expression of Xhox.1ab genes and alters mesodermal determination in Xenopus laevis. Genes Dev. 5, 1321-1332.

Slack, J. M. W. and Forman, D. (1980). An interaction between dorsal and ventral regions of the marginal zone in early amphibian embryos. $J$. Embryol. exp. Morph. 56, 283-299.

Slack, J. M. W. and Tannahill, D. (1992). Mechanism of anteroposterior axis specification in vertebrates. Lessons from the amphibians. Development 114, 285-302.

Slack, J. M. W., Darlington, B. G., Heath, J. K. and Godsave, S. F. (1987). Mesoderm induction in early Xenopus embryos by heparinbinding growth factors. Nature 326, 197-200.

Small, S., Kraut, R., Hoey, T., Warrior, R. and Levine, M. (1991). Transcriptional regulation of a pair-rule stripe in Drosophila. Genes Dev. 5, 827-839.

Smith, J. C. (1989). Mesoderm induction and mesoderm-inducing factors in early amphibian development. Development 105, 665-677.

Smith, J. C. and Slack, M. W. (1983). Dorsalization and neural induction: properties of the organizer in Xenopus. J. Embryol. exp. Morphol. 78 299-317.

Smith, J. C., Dale, L. and Slack, M. W. (1985). Cell lineage labels and region-specific markers in the analysis of inductive interactions. $J$. Embryol. exp. Morph. 89, 317-331.

Smith, J. C., Price, B. M. J., Green, J. B. A., Weigel, D. and Hermann, B. G. (1991). Expression of a Xenopus homolog of brachyury (T) is an immediate-early response to mesoderm induction. Cell 67, 79-87.

Smith, L. C., Britten, R. J. and Davidson, E. H. (1992). SpCoel1, a sea urchin profilin gene expressed specifically in coelomocytes in response to injury. Mol. Biol. Cell 3, 403-414.

Smith, W. C. and Harland, R. M. (1991). Injected Xwnt-8 RNA acts early in Xenopus embryos to promote formation of a vegetal dorsalizing center. Cell 67, 753-765.

Smith, W. C. and Harland, R. M. (1992). Expression cloning of noggin, a new dorsalizing factor localized to the organizer in Xenopus embryos. Cell 70, 829-840.

Smith, W. C., Knecht, A. K., Wu, M. and Harland, R. M. (1993). Secreted noggin protein mimics the Spemann organizer in dorsalizing Xenopus mesoderm. Nature 361, 547-549.

Sokol, S. and Melton, D. A. (1991). Pre-existent pattern in Xenopus animal pole cells revealed by induction with activin. Nature 351, 409-411.

Sokol, S. and Melton, D.A. (1992). Interaction of wnt and activin in dorsal mesoderm induction in Xenopus. Dev. Biol. 154, 348-355.

Sokol, S., Christian, J. L., Moon, R. T. and Melton, D. A. (1991). Injected Wnt RNA induces a complete body axis in Xenopus embryos. Cell 67, 741-752.

Spemann, H. (1938). Embryonic Development and Induction. New Haven: Yale University Press.

Stanojevic, D., Small, S. and Levine, M. (1991). Regulation of a segmentation stripe by overlapping activators and repressors in the Drosophila embryo. Science 254, 1385-1387.

Stewart, R. M. (1990). The active inducing center of the embryonic body axis in Xenopus. Ph.D. Thesis, UC Berkeley.

Stewart, R. M. and Gerhart, J. C. (1990). The anterior extent of dorsal development of the Xenopus embryonic axis depends on the quantity of organizer in the late blastula. Development 109, 363-372.

St. Johnston, D. and Nusslein-Volhard, C. (1992). The origin of pattern and polarity in the Drosophila embryo. Cell 68, 201-219.

Struhl, G., Johnston, P. and Lawrence, P. A. (1992). Control of Drosophila body pattern by the hunchback morphogen gradient. Cell 69 , 237-249.

Tabin, C. J. (1991). Retinoids, homeoboxes, and growth factors: Toward molecular models for limb development. Cell 66, 199-217.

Taira, M., Jamrich, M., Good, P. J. and Dawid, I. B. (1992). The LIM domain-containing homeobox gene Xlim-1 is expressed specifically in 
the organizer region of Xenopus gastrula embryos. Genes Dev. 6, 356366.

Takahasi, Y., Bontoux, M. and Le Douarin, N. M. (1991). Epitheliomesenchymal interactions are critical for Quox 7 expression and membrane bone differentiation in the neural crest derived mandibular mesenchyme. EMBO J. 10, 2387-2393.

Takahashi, Y., Monsoro-Burg, A.-H., Bontoux, M. and Le Douarin, N. M. (1992). A role for Quox-8 in the establishment of the dorsoventral pattern during vertebrate development. Proc. Natl. Acad. Sci. USA 89, 10237-10241.

Takeichi, M. (1987). Cadherins: A molecular family essential for selective cell-cell adhesion and animal morphogenesis. Trends Genet. 3, 213-217.

Takeichi, M. (1991). Cadherin cell adhesion receptors as a morphogenetic regulator. Science 251, 1451-1455.

Tanaka, S. and Dan, K. (1990). Study of the lineage and cell cycle of small micromeres in embryos of the sea urchin, Hemicentrotus pulcherrimus. Dev. Growth Differ. 32, 145-156.

Thomsen, G., Woolf, T., Whitman, M., Sokol, S., Vaughan, J., Vale, W. and Melton, D. A. (1990). Activins are expressed early in Xenopus embryogenesis and can induce axial mesoderm and anterior structures. Cell 63, 485-493.

Thiebaud, P., Goodstein, M., Calzone, F. J., Thézé, N., Britten, R. J. and Davidson, E. H. (1990). Intersecting batteries of differentially expressed genes in the sea urchin embryo. Genes Dev. 4, 1999-2010.

Topol, J., Dearolf, C. R. Prakash, K. and Parker, C. S. (1991). Synthetic oligonucleotides recreate Drosophila fushi tarazu zebra-stripe expression. Genes Dev. 5, 855-867.

Tremml, G. and Bienz, M. (1992). Induction of labial expression in the Drosophila endoderm: response elements for $d p p$ signaling and for autoregulation. Development 116, 447-456.

Turing, A. M. (1952). The chemical basis of morphogenesis. Roy. Soc. Lond, Phil. Trans. 237, 1952-1954

Van Doren, M., Powell, P. A., Pasternak, D., Singson, A. and Posakony,
J. W. (1992). Spatial regulation of proneural gene activity: auto- and cross-activation of achaete is antagonized by extramacrochaetae. Genes Dev. 6, 2592-2605.

Venuti, J. M., Goldberg, L., Chakraborty, T., Olson, E. N. and Klein, W. H. (1991). A myogenic factor from sea urchin embryos capable of programming muscle differentiation in mammalian cells. Proc. Natl. Acad. Sci. USA 88, 6219-6223.

von Dassow, G., Schmidt, J. and Kimelman, D. (1993). Induction of the Xenopus organizer: expression and regulation of Xnot, a novel FGF and activin-inducible homeobox gene. Genes Dev. 7, 355-366.

Wessel, G. M. and McClay, D. R. (1985). Sequential expression of germlayer specific molecules in the sea urchin embryo. Dev. Biol. 111, 451463.

Wessel, G. M. and McClay, D. R. (1987). Gastrulation in the sea urchin embryo requires the deposition of crosslinked collagen with the extracellular matrix. Dev. Biol. 121, 149-165.

Wessel, G. M., Goldberg, L., Lennarz, W. J. and Klein, W. H. (1989). Gastrulation in the sea urchin is accompanied by the accumulation of an endoderm-specific mRNA. Dev. Biol. 136, 526-536.

Wessel, G. M., Zhang, W. and Klein, W. H. (1990). Myosin heavy chain accumulates in dissimilar cell types of the macromere lineage in the sea urchin embryo. Dev. Biol. 140, 447-454.

Wolpert, L. (1971). Positional information and pattern formation. Curr. Topics Dev. Biol. 6, 183-224.

Yokouchi, Y., Ohsugi, K., Sasaki, H. and Kuroiwa, A. (1991). Chicken homeobox gene Msx-1: Structure, expression in limb buds and effect of retinoic acid. Development 113, 431-444.

Zhang, C.-C., Muller, J., Hoch, M., Jäckle, H. and Bienz, M. (1991). Target sequences for hunchback in a control region conferring Ultrabithorax expression boundaries. Development 113, 1171-1179.

(Accepted 9 March 1993) 